\title{
High Temperature Superconducting Maglev Measurement System
}

\author{
Jia-Su Wang and Su-Yu Wang \\ Applied Superconductivity Laboratory of Southwest Jiaotong University \\ P. R. China
}

\section{Introduction}

Melt-textured rare-earth Ba-Cu-O (REBCO, RE=Nd, Sm, Eu, Gd, etc.) bulk samples have high critical current density and high critical magnetic flux, which can produce a strong levitation force and a stable equilibrium. The high temperature superconducting (HTS) REBCO bulk may be cooled using liquid nitrogen instead of liquid helium to reduce the initial construction and running cost in practical application systems. This makes HTS bulks particularly attractive for the applications in magnetic bearings (Moon, 1990), flywheel energy storage devices (Bomemann, 1995), and Maglev vehicle (Wang J. et al., 2002). In order to investigate the magnetic levitation properties (levitation force, guidance force, trapping flux, and so on) of the HTS Maglev vehicle over a permanent magnet (PM) guideway, SCML-01 HTS Maglev measurement system was developed at the Applied Superconductivity Laboratory (ASCLab) of Southwest Jiaotong University in China (Wang J. et al., 2000). The measurement system includes a liquid nitrogen vessel, a permanent magnet guideway (PMG), data collection and processing capabilities, a mechanical drive and an Autocontrol feature. The bottom wall of the vessel has a thickness of $3.0 \mathrm{~mm}$. The PMG has a length of $920 \mathrm{~mm}$, for which its magnetic induction reaches up to $1.2 \mathrm{~T}$. The measuring process is controlled by a computer.

The SCML-01 measurement system is capable of performing real time measurements of Maglev properties through a combination of one or many $\mathrm{YBaCuO}$ bulks and one PM or several PMGs. This set up was especially employed on board the HTS Maglev equipment over one and two PMGs. The on board Maglev equipment includes a rectangular-shaped liquid nitrogen vessel containing $\mathrm{YBaCuO}$ bulk superconductors.

Based on the original research results (Wang J. \& S. Wang, 2005a; Song, 2006) from SCML-01, the first man-loading HTS Maglev test vehicle in the world was successfully developed in 2000 (Wang J. et al., 2002). After 2004, several HTS Maglev vehicle prototypes over a PMG followed in Germany, Russia, Brazil, Japan and Italy (Schultz et al., 2005; Kovalev et al., 2005; Stephan et al., 2004; Okano et al., 2006; D'Ovidio et al., 2008).

Given the lack in measurement functions and measurement precision of the SCML-01, after five years, the HTS Maglev Measurement System (SCML-02) with more functions and higher precision was developed to extensively investigate the Maglev properties of $\mathrm{YBaCuO}$ bulks 
over a PM or PMG (Wang S. et al., 2007). The new features in this measurement system are unique and they include: higher measurement precision, instant measurement upon the movement of the measured HTS sample, automatic measurements of both levitation and guidance forces, dynamic rigidity, three dimensional simultaneous movement of the HTS sample, relaxation measurement of both levitation and guidance forces, and so on.

All these experimental parameters are very helpful to evaluate the load ability of the HTS Maglev vehicle. But the running performance over a PMG cannot be measured by the above mentioned measurement systems.

For the further development of the HTS Maglev vehicle in engineering application, the dynamic Maglev properties should be clearly understood. In order to investigate the dynamic characteristics behavior of the HTS Maglev, an HTS Maglev dynamic measurement system (SCML-03) was designed and successfully developed (Wang J. et al., 2008). The system's main component constitutes of a circular PMG, along with a liquid nitrogen vessel, data acquisition and processing features, mechanical drive, autocontrol, etc. The PMG is fixed along the circumferential direction of a big circular disk with a diameter of 1,500 mm. The maximum linear velocity of the PMG is about $300 \mathrm{~km} / \mathrm{h}$ when the circular disk rotates around the central axis at $1280 \mathrm{rpm}$. The liquid nitrogen vessel along with the assembly of HTS bulk samples is placed above the PMG of the dynamic testing. The liquid nitrogen vessel is made to not be rigid along the three principal axes but instead, measurement sensor devices are attached. These sensors can detect weak changes of force along the threeprincipal directions.

The principles, methods, structure, functions, and specifications of the several HTS Maglev measurement system are discussed in detail in this chapter. These systems were developed at the Applied Superconductivity Laboratory (ASCLab) of Southwest Jiaotong University, P. R. China (Wang J. et al., 2000; Wang S. et al., 2007; Wang J. et al., 2008), and they have unique functions towards the measurement of the HTS Maglev.

\section{HTS Maglev measurement system}

The potential engineering applications mentioned above are based on high quality HTS bulk samples, and it is especially important to investigate the magnetic levitation properties between the YBCO bulk and the permanent magnet. HTS bulk preparation methods and enhancements are still in progress. The axial symmetry magnetic levitation properties are fully researched, and there are comprehensive review papers elsewhere (Moon, 1994; Hull, 2000; Ma, 2003; Deng, 2008a; 2009a). The Maglev properties between the YBCO bulk and the PMG are discussed by this chapter author (Wang J. \& S. Wang, 2005a; Song, 2006; Wang J. et al., 2009).

\subsection{Brief History of HTS magnetic levitation}

The levitation of a $\mathrm{NdFeB}$ permanent magnet $0.7 \mathrm{~cm}^{3}$ above a piece of $2.5 \mathrm{~cm}$-diameter, 0.6 $\mathrm{cm}$ thick disk of YBCO bulk superconductor bathed in liquid nitrogen was observed by Hellman et al. (Hellman, 1988). While Peter et al. (Peter, 1988) had observed the very stable suspension of YBCO samples in the divergent magnetic field, they discovered the suspending phenomenon below the permanent magnet. 
An HTS Maglev measurement system was developed (Wang J., 2000; 2001) in order to investigate magnetic levitation properties of the HTS YBCO bulk above a PMG. A series of the properties, for example, levitation force, guidance force, levitation stiffness, etc., of YBCO bulk HTS over a PMG were investigated with this measurement system. The measurement system includes liquid nitrogen vessel (circular and rectangular-shaped), permanent magnet guideway (PMG), data collection and processing, mechanical drive and control system, and scanning of the magnetic flux.

\subsection{Permanent magnet guideway (PMG)}

Fig. 1 shows the cross-sectional drawing of the PMG. Two construction cross-sectional drawings of the PMG are shown. The PMG is composed of normal permanent magnets and iron plate. The arrows represent magnetic poles where the arrowhead represents north. The length of the PMG is $920 \mathrm{~mm}$, and the concentrating magnetic induction of the PMG is up to $1.2 \mathrm{~T}$ at the surface.

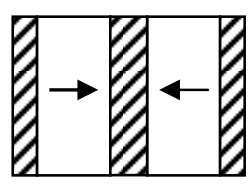

(a)

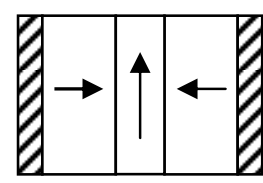

(b)

Fig. 1. Cross sectional view of the PMG $\mathbb{Z}$ iron $\rightarrow \mathrm{NdFeB}$
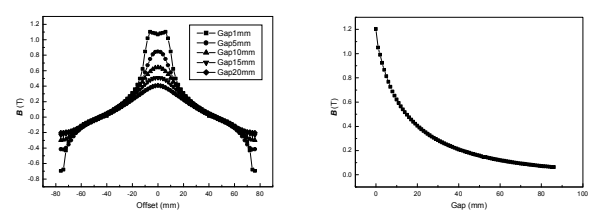

Fig. 2. Measured results of the PMG's magnetic field along the transverse (lift) and vertical (right) directions.

In Fig. 2, the magnetic field of the center of the PMG is stronger than that of any other position, and it decreases rapidly with the increasing of the gap from the surface of the PMG. The surface magnetic field of a single PM is about $0.45 \mathrm{~T}$, while the surface concentrating magnetic flux density of the PMG (a) is up to $1.2 \mathrm{~T}$. The magnetic flux density is $0.4 \mathrm{~T}$ at $20 \mathrm{~mm}$ above the surface of the PMG which is equivalent to the surface magnetic field of a single PM. The PMG shown in Fig. 2(a) was not solely used for HTS bulk measurements.

\subsection{Liquid nitrogen vessel}

One of the important technologies developed on board the HTS Maglev vehicle was the thin walled liquid nitrogen vessel. The thickness of said liquid nitrogen vessel wall was generally not considered, and its main feature is its low evaporation rate. Since the superconductors are levitated above the PMG in the HTS Maglev measurement system, a thin bottom wall of the vessel was needed. Only with a thin bottom wall, will a net levitation gap clearance between the outside (bottom) wall of the vessel and the guideway be high. A columnar liquid nitrogen vessel with a thin bottom wall of only $3 \mathrm{~mm}$ was developed (Wang S., 2001b) in order to verify the possibility of further developing large sized vessel with thin walls that 
can be used on the Maglev vehicle. Both the schematic diagram and vapor rate of the liquid nitrogen vessel are shown in Fig. 3.

The outline size of the vessel has an external diameter of $200 \mathrm{~mm}$, an internal diameter of $150 \mathrm{~mm}$, and a height of $250 \mathrm{~mm}$. The liquid nitrogen vessel can operate continuously over 16 hours, and can hold 7 blocks of YBCO samples of $30 \mathrm{~mm}$ in diameter. The vessel was used successfully to measure the levitation forces of YBCO bulk over a magnetic guideway. During the experiment, the $\mathrm{YBCO}$ is fixed and secured at the bottom of the columnar liquid nitrogen vessel.

According to the experiment results mentioned above, a rectangular-shaped liquid nitrogen vessel on board the HTS Maglev vehicle was developed (Su-Yu Wang, 2003). The wall of the rectangle vessel was made even thinner, and the bottom wall's thickness is only of $3 \mathrm{~mm}$. The schematic diagram of the rectangular-shaped liquid nitrogen vessel is shown in Fig. 4 . Its outside outline size is $150 \mathrm{~mm} \times 516 \mathrm{~mm}$. The inside size is $102 \mathrm{~mm} \times 470 \mathrm{~mm}$, and the height is $168 \mathrm{~mm}$. This particular liquid nitrogen vessel can operate continuously for over 6 hours. The rectangular-shaped vessel was used in the measurement of the levitation force of numerous YBCO samples. The vessel was successfully employed on board the HTS bulk Maglev measurement system.
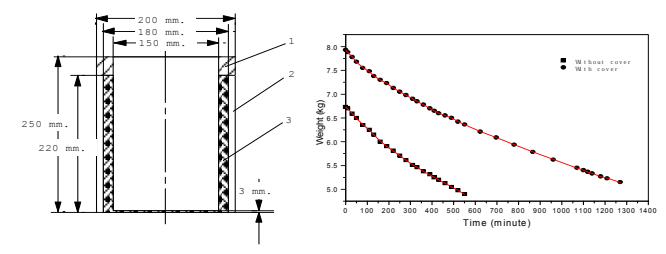

Fig. 3. Schematic diagram and vapor rate of the columnar liquid nitrogen vessel with thin wall

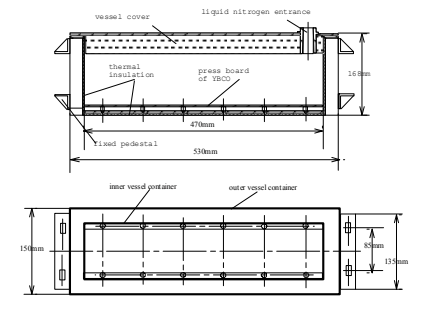

Fig. 4. Schematic diagram of the rectangular-shaped liquid nitrogen vessel

\subsection{HTS Maglev measurement system}

Fig. 5 shows the schematic diagram of the HTS Maglev measurement system. During the experiment, the $\mathrm{YBCO}$ is placed in the columnar liquid nitrogen vessel which is positioned above the PMG. The YBCO is zero field cooled and the vessel is allowed to move up and down at different speeds. The horizontal drive platform is used to measure the guidance force (stable equilibrium force along longitudinal orientation of guideway). The drive device of three dimensions can make scanning measurements of the magnetic field of the PMG and trapped flux inside an HTS.

The specifications of the SCML-01 measurement system are: vertical maximal displacement of $200 \mathrm{~mm}, \pm 0.1 \mathrm{~mm}$ precision, $\pm 2,000 \mathrm{~N}$ vertical maximal support force, $0.2 \%$ precision; 100 $\mathrm{mm}$ guideway horizontal maximal displacement, $\pm 0.1 \mathrm{~mm}$ precision, $1,000 \mathrm{~N}$ of horizontal maximal support force, and $0.1 \%$ precision. The trapping flux of high $T_{\mathrm{c}}$ superconductors and the magnetic induction of the guideway can be scanned in the range of $100 \mathrm{~mm} \times 100 \mathrm{~mm}$. 
In the measurement, the YBCO HTS bulk sample is fixed at the bottom of the thin wall liquid nitrogen vessel and cooled to go into the superconducting state in a zero magnetic field. Secondly, the vessel is fixed at a connecting fixture with a servo electromotor. In order

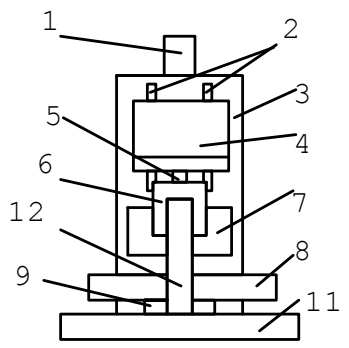

(a)

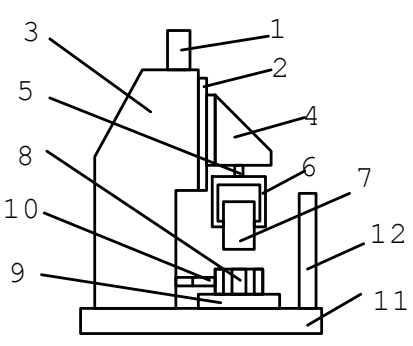

(b)

Fig. 5. Scheme of HTS Maglev measurement system.

1) Servo motor , 2) Vertical guided way, 3) Vertical column, 4) Cantlever, 5) Vertical sensor, 6) Fix frame of vessel, 7) Liquid nitrogen vessel, 8) Permanent magnet guideway (PMG), 9) Horizontal drive platform, 10) Horizontal sensor, 11) Base, 12) Drive device of three dimension

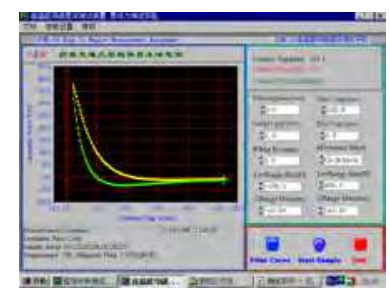

(a) Levitation force

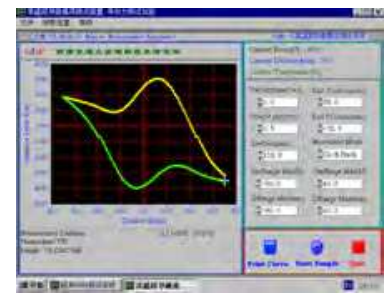

(b) Guidance force

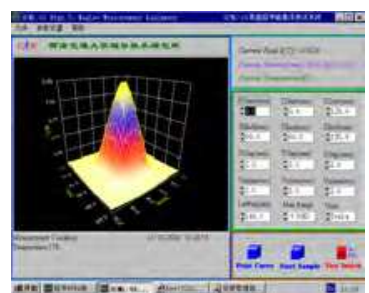

(c) Scanning trapping flux

Fig. 6. Main interfaces of the measurement results

to avoid collision between the bottom of the vessel and the surface of PMG, there is still a gap of $1.5 \mathrm{~mm}$ left in between the bottom of the vessel and the surface of the PMG when the vessel is lowered to the lowest point, so the minimum gap is $5 \mathrm{~mm}$ between the bottom of the sample and the surface of PMG. The vessel first moves downward, after reaching the lowest point, then moves upward at a speed of $2 \mathrm{~mm} / \mathrm{s}$, and the computer samples a data every 0.5 second. The system can make real time measurements of one or many superconductors. The measurement process is controlled by a computer. The main interfaces of the measurement results of the magletic levitation force, guidance force, and scanning magnetic field of an HTS trapping flux are shown in Fig. 6.

The SCML-01 measurement system is capable to make real time measurement of Maglev properties with one to many YBCO pieces and with a PM or PMGs. This set up was especially employed in on board HTS Maglev equipment over one or two PMGs (Fig. 7). The on board Maglev equipment includes a rectangular-shaped liquid nitrogen vessel and 
an array of YBCO bulk superconductors. Fig. 7 is a picture of the HTS Maglev measurement system. Three types of liquid nitrogen vessels are shown in Fig. 7, a columnar vessel, a rectangle vessel, and two rectangle vessels.

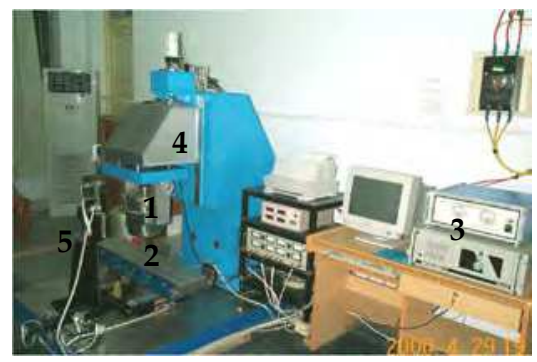

(a) a columnar vessel

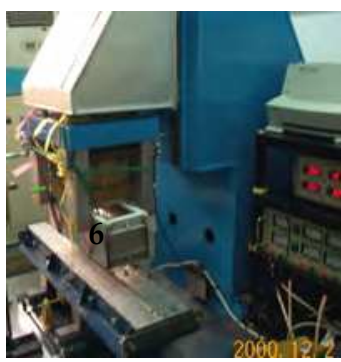

(b) a rectangle vessel

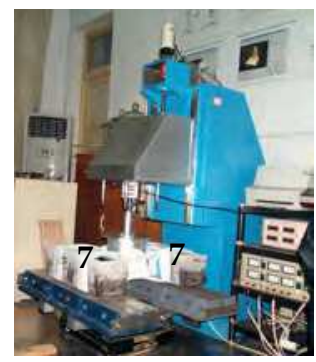

(c) two rectangle vessels

Fig. 7. Photos of HTS Maglev measurement system SCML-01

1 liquid nitrogen vessel, 2 permanent magnet guideway (PMG), 3 data collection and processing, 4 mechanical drive and Autocontrol, 5 scan magnetic flux, 6 a rectangle-shape vessel, 7 two rectangle-shape vessels

Based on the original research results (Wang J. \& S. Wang, 2005a; Song, 2006) from SCML-01, the first man-loading HTS Maglev test vehicle in the world was successfully developed in 2000 (Wang et al., 2002). Many of these research results (Ren, 2003; Wang X. R. 2003; Song, 2004; Wang X.Z. 2004; Wang J. \& S. Wang, 2005c) were obtained by the SCML-01 HTS Maglev measurement system.

\section{Measurement technology of HTS Maglev vehicle}

\subsection{The first man-loading HTS Maglev test vehicle in the world}

High-temperature superconductors are highly attractive because it can operate at liquid nitrogen temperature. Soon after the stable levitation of a PMG above a YBCO bulk superconductor bathed in liquid nitrogen was observed by Hellman et al., (Hellman et al., 1988), people began to consider its applications to superconducting Maglev vehicles. The levitation forces of YBCO bulks over a PMG have been reported (Wang S. et al., 2001a). The onboard HTS Maglev equipment is a key component of the HTS Maglev vehicle that has been developed (Wang S. et al., 2002). The first man-loading HTS Maglev vehicle in the world was tested successfully on December 31, 2000 at the Applied Superconductivity Laboratory of Southwest Jiaotong University, China (Wang J. et al., 2002; 2005b; Wang S. et al., 2001b).

The PMG consists of two parallel PM tracks, whose concentrating magnetic field at a height of $20 \mathrm{~mm}$ is about $0.4 \mathrm{~T}$. The total length of the PMG is $15.5 \mathrm{~m}$. The HTS Maglev provides inherent stability along both the vertical and lateral directions, so there is no need to control the vehicle along these two directions. The only control system used are linear motors as driving and breaking devices. The 8 onboard HTS Maglev equipment assemblies (Wang S. et al., 2003) are connected rigidly on the two sides of vehicle body, with 4 Maglev equipment 
assemblies on each side. The vehicle body (Fig. 8(b)) is 2,268 mm long, 1,038 mm wide and $120 \mathrm{~mm}$ high. Both the linear motor of the vehicle and the PMG are under the vehicle body.

The vehicle body was lifted by a hydraulic pressure until the gap between the bottom of liquid nitrogen vessels and the surface of the PMG was larger than $75 \mathrm{~mm}$. Then the HTS

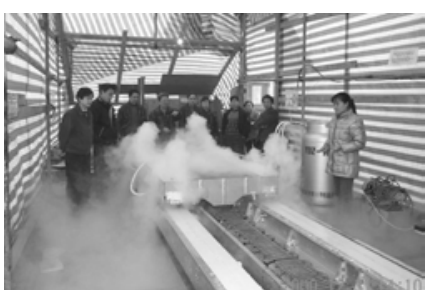

(a)

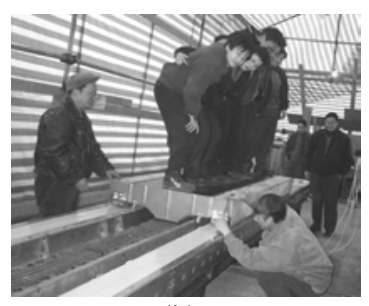

(b)

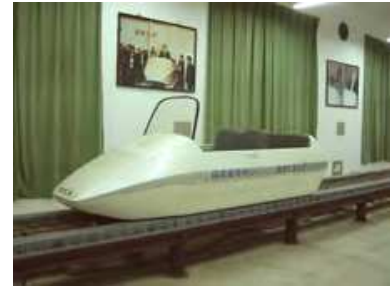

(c)

Fig. 8. (a) Photograph of the first pouring of liquid nitrogen; (b) The net levitation gap of the HTS Maglev test vehicle body was more than $20 \mathrm{~mm}$ when five people stood on the vehicle; (c) Photograph of the HTS Maglev test vehicle with outer casing.

bulks were cooled with liquid nitrogen. Fig. 8(a) shows the historic moment of the first pouring of liquid nitrogen into the onboard vessels. In Fig. 8(c) we can see the two tracks and the vehicle body.

The net levitation gap of the HTS Maglev test vehicle body is more than $20 \mathrm{~mm}$ when five people stood on the vehicle, and the levitation height of the vehicle body was $33 \mathrm{~mm}$ when the five people got off the vehicle (Fig. 8(b)). Fig. 8(c) shows the photograph of the HTS Maglev test vehicle with an outer casing. The external outline size of of the vehicle with a shell is $3.5 \mathrm{~m}$ long, $1.2 \mathrm{~m}$ wide, and $0.8 \mathrm{~m}$ high. There are 4 seats in the HTS Maglev vehicle. The total levitation force of the entire Maglev vehicle was measured to be 6,351 $\mathrm{N}$ at the net levitation clearance gap of $20 \mathrm{~mm}$, and 7,850 N at the net levitation gap of $15 \mathrm{~mm}$ in July 2001. The net levitation gap is the distance between the PMG's upper surface and the liquid nitrogen vessel's bottom.

\subsection{Measurement of essential parameters of HTS Maglev test vehicle}

The onboard HTS Maglev equipment is of most importance to the HTS Maglev vehicle. There are 8 HTS Maglev equipment assemblies on the vehicle body, each composed of 43 YBCO bulk pieces inside a liquid nitrogen vessel (Wang S. et al., 2001b).

The YBCO bulks are $30 \mathrm{~mm}$ in diameter and 17-18 $\mathrm{mm}$ in thickness. The YBCO bulks are sealed by a special method in order to preserve the integrity and quality of the superconductors. The melt-textured YBCO bulk superconductors are fixed firmly at the bottom of each of the liquid nitrogen vessels, and cooled by liquid nitrogen. The levitation forces of the 8 HTS maglev equipments were measured and described by Wang et al. (Wang J. et al., 2003a).

Fig. 9(a) shows the levitation force of a single onboard HTS Maglev equipment over the PMG is 1,227 $\mathrm{N}$ at the levitation gap of $15 \mathrm{~mm}$, and the levitation force was 1,593 $\mathrm{N}$ at the levitation gap of $8 \mathrm{~mm}$. Fig. 9(b) shows the levitation forces of the 8 onboard Maglev equipment assemblies over the PMG are different. There were some differences between 
each of the equipment assemblies. For example, the levitation force of Maglev equipment No. 7 is 1,493 $\mathrm{N}$ at the levitation gap of $10 \mathrm{~mm}$, and 1,227 $\mathrm{N}$ of $15 \mathrm{~mm}$. The levitation force of Maglev assembly No. 3 is 1,091 $\mathrm{N}$ at the levitation gap of $10 \mathrm{~mm}$, and $902 \mathrm{~N}$ of $15 \mathrm{~mm}$. Fig. 9(c) shows the total levitation forces of the 8 onboard Maglev equipment assemblies.

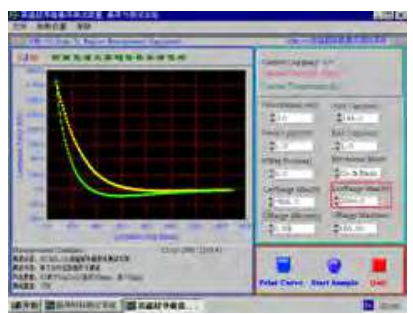

(a)

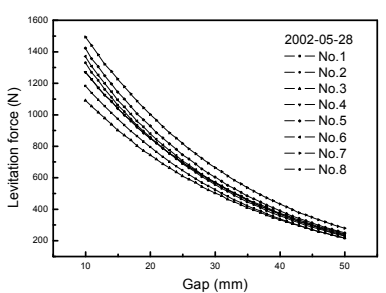

(b)

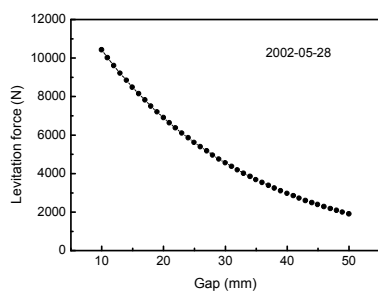

(c)

Fig. 9. (a) The measured interface of a single rectangle-shape vessel, (b) Measured results of eight rectangle-shape vessels of on board single HTS magnetic levitation equipment (43 pieces of YBCO bulks), and (c) The total levitation force of 8 onboard HTS Maglev equipments over the PMG.

The total levitation force of 8 onboard Maglev equipments assemblies yielded a force of $10,431 \mathrm{~N}$ at the levitation gap of $10 \mathrm{~mm}$, and $8,486 \mathrm{~N}$ at $15 \mathrm{~mm}$.

3.3 Guidance forces of the HTS Maglev vehicle(Wang S. et al., 2003b, Wang X.R. et al., 2005) The guidance force defines the lateral stability of the Maglev vehicle when either standstill or moving. The lateral guidance force is dependent on the trapped flux in the bulk superconductors, so the larger the amount of trapped flux, the stronger the guidance force. This is a distinctive character of the bulk HTS Maglev vehicle. This sort of Maglev vehicle with bulk HTS does not need any lateral stability control systems, which makes it superior to other conventional Maglev vehicle systems. The guidance forces are large and sufficient enough to guide the vehicle when large levitation forces are ensured.

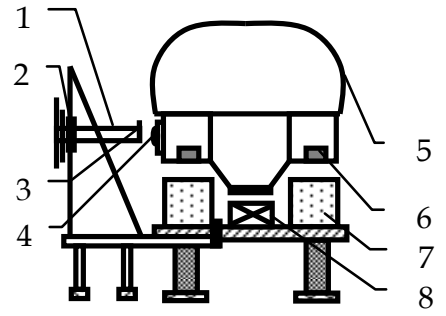

(a)

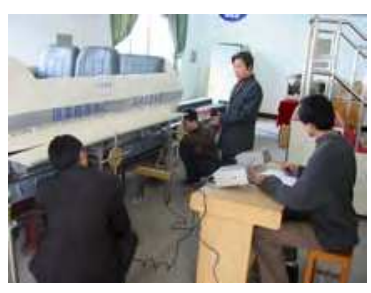

(b)

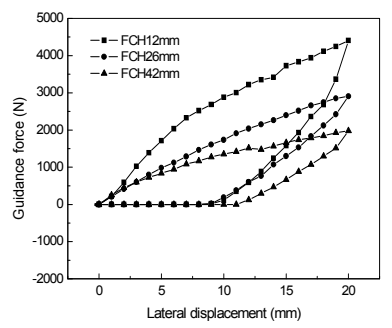

(c)

Fig. 10. Sketch (lift) and Photograph (right) of measuring equipment of guidance force of vehicle 
1 Horizontal propulsion system; 2 Vertical propulsion system; 3 Screw of adjusting zero; 4 Force sensor; 5 vehicle body; 6 HTS; 7 Permanent magnetic railway; 8 Linear motor The measuring equipment of the guidance force of the entire HTS Maglev vehicle is deppicted in Fig. 10(a). The set up includes two probing levers and two sets of force sensors. The force sensors are fixed on the vehicle. Each set of the propulsion system can move in both the horizontal and vertical directions so that they can measure the guidance force of the entire vehicle at different levitation gaps. Two sets of propulsion systems are connected by a chain with a synchronization precision of $0.5 \mathrm{~mm}$. The moving range of the propulsion system along the horizontal direction is 0 to $20 \mathrm{~cm}$ and moving precision: $1 \mathrm{~mm}$; and along the vertical direction a range from 0 to $10 \mathrm{~cm}$, vertical moving precision: $1 \mathrm{~mm}$. A photograph of the measuring equipment of guidance force is shown in Fig 10(b).

The experimental results of the guidance force under the maximum lateral distance of 20 $\mathrm{mm}$ are shown in Fig 10(c). The data shows that the lateral guidance forces have a large hysteresis effect. The guidance forces rise rapidly when the vehicle leaves its initial position, and the increase rate becomes smaller as the vehicle becomes further away from its original position Fig 10(c). The guidance forces drop rapidly when vehicle moves back to its initial positions from the maximum lateral displacement of $20 \mathrm{~mm}$, and vanishes at about $10 \mathrm{~mm}$. This indicates that the range of effective lateral displacement is smaller than $10 \mathrm{~mm}$. It can be seen from Fig 10(c) that the lateral guidance forces of the entire HTS Maglev vehicle under different field cooling heights $(\mathrm{FCH})$ are sufficiently large enough. The guidance forces with displacements $20 \mathrm{~mm}$ are 4,407 N, 2,908 N, and 1,980 N for field cooling heights of $12 \mathrm{~mm}, 26 \mathrm{~mm}$, and $42 \mathrm{~mm}$, respectively.

The HTS Maglev vehicle can return to its initial position after a lateral displacement from 0 $\mathrm{mm}$ to $6 \mathrm{~mm}$, whereas this did not happen when the lateral displacement was from $0 \mathrm{~mm}$ to $20 \mathrm{~mm}$. For example, there is a zero guidance force at the displacement $9 \mathrm{~mm}$ when $\mathrm{FCH}$ is $26 \mathrm{~mm}$. The measured guidance pull force, which makes the vehicle return to the initial rest position, was $1,214 \mathrm{~N}$ when the $\mathrm{FCH}$ was $26 \mathrm{~mm}$. Again, this force is sufficiently large enough to keep the vehicle laterally stable.

\subsection{Long-term stability of the HTS Maglev vehicle in 2001 2003(Wang J. et al., 2004)}

Fig. 11 shows the total levitation force of eight liquid nitrogen vessels over the PGM at different gaps. In July 2001, the levitation force was found to be $8,940 \mathrm{~N}$ at the levitation gap of $15 \mathrm{~mm}$ and 7,271 $\mathrm{N}$ at the levitation gap of $20 \mathrm{~mm}$. The total levitation force of eight liquid nitrogen vessels over the PMG in March 2003 was 8,000 N at the levitation gap (deduct 3 $\mathrm{mm}$ bottom thickness of liquid nitrogen vessel) of $15 \mathrm{~mm}$.

The measurement results are measured by HTS Maglev measurement system SCML-01 (Wang J. et al., 2000) in July 2001, December 2001, May 2002, and March 2003, respectively.

Fig. 11 shows the levitation forces of the entire HTS Maglev vehicle to be 8,486 N at the levitation gap of $15 \mathrm{~mm}$ and 6,908 $\mathrm{N}$ at the levitation gap of $20 \mathrm{~mm}$ in May 2002. At a gap of $30 \mathrm{~mm}$, there was a $46 \%$ decrease of the levitation force compared to the gap of $15 \mathrm{~mm}$.

During the 10 month period from July 2001 to May 2002, the levitation force was found to only decrease by $5.0 \%$ at the levitation gap of $20 \mathrm{~mm}$. 


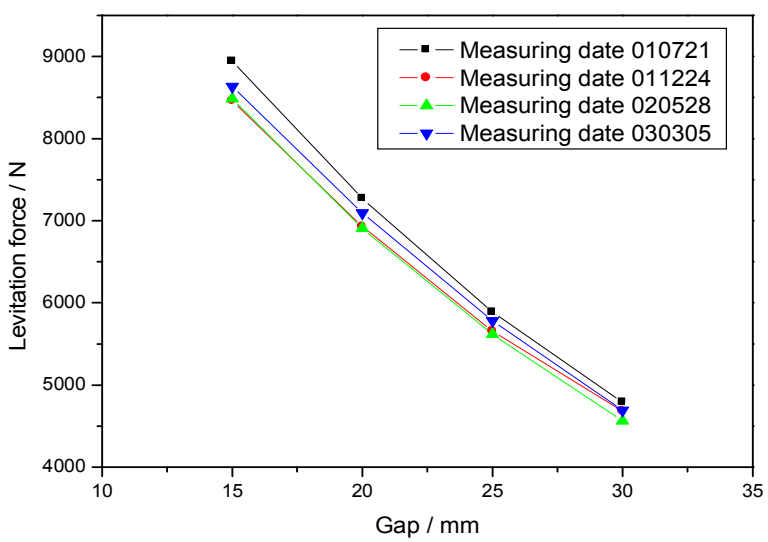

Fig. 11. Change of total levitation force of the entire HTS Maglev vehicle

The data set of levitation forces for the March 2003 was slightly higher than the May 2002 data set was due to one of the PMG was not laid to overlap accurately.

The comparison of total levitation forces of the entire HTS Maglev vehicle in July 2001 with one in May 2002 showed a levitation force decrease of a $5.1 \%, 5.0 \%, 4.6 \%$, and $4.8 \%$ at the levitation gaps of $15 \mathrm{~mm}, 20 \mathrm{~mm}, 25 \mathrm{~mm}$, and $30 \mathrm{~mm}$, respectively. All data are nearly the same, i.e., levitation force decrease is about $5.0 \%$ at different levitation gaps.

The levitation forces became small after two years. Up to this day, (September 2009) over 27,000 passengers have taken a ride on the Maglev vehicle, and the total recorded shuttle mileage is about $400 \mathrm{~km}$. Experimental results indicate long-term stability of the HTS Maglev vehicle is better when in the static mode than experiment results mentioned were obtained above when the HTS Maglev vehicle was operating at low speeds. The behavior of an HTS Maglev vehicle is very different at high speeds. Therefore, the investigation of the dynamic properties of the HTS maglev vehicle at high speed operation is extremely important.

3.5 Long-term stability of on-board bulks YBCO in 2001 2009(Liu et al., 2009)

In order to evaluate the long-term operation stability of the HTS bulks for practical application, the levitation performance of bulk YBCO samples are inverstigated by the SCML-02 setup throughout 2001 to 2009. The same bulk YBCO pieces (A5) used in 2000 still remain placed on the man-loading HTS maglev vehicle and have been running for nearly nine years. The measurement results of the levitation force (Fig. 12), hysteresis, and relaxation (Fig. 13) of the bulks $\mathrm{YBCO}$, which were under the liquid nitrogen temperature ( 77K) were measured by the SCML-02 HTS Maglev measurement system in June, 2009. A batch of YBCO samples were synthesized in 2007 (07-1) and in 2008 (08-1), and some of these samples were loaded in 2007 and others in latter times. This was to analyze the variation of levitation performances of different bulk YBCO samples during different times after fabrication of the YBCO. 


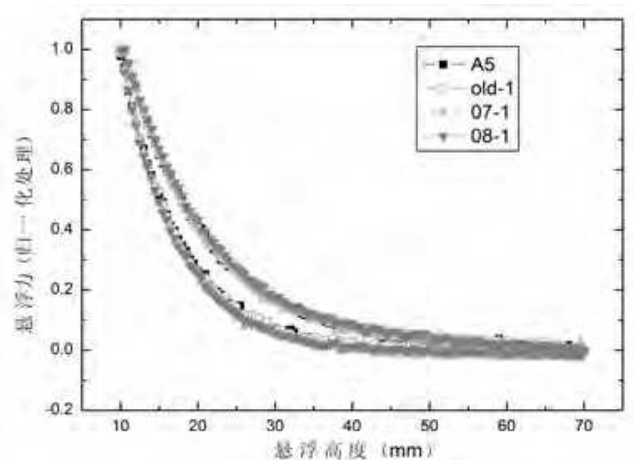

Fig. 12. Measurenment results of levitation force

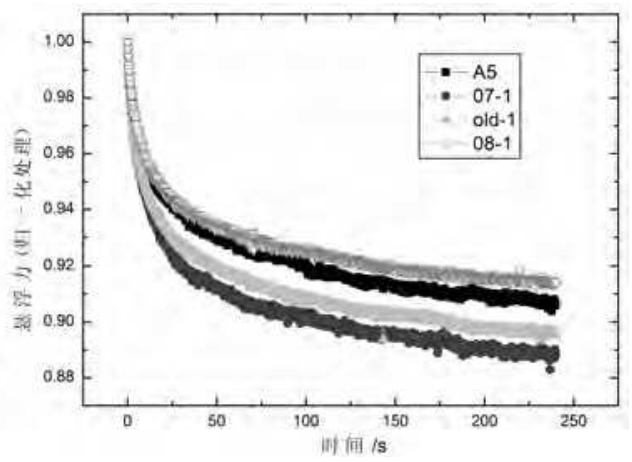

Fig. 13. Measurenment results of levitation force relaxation

(A5) is onboard bulk YBCO in 2000; (Old-1) is bulk YBCO of not loaded in 2000; (07-1) is new in 2007; (08-1) is new in 2008

Fig 12. is the comparison of the levitation force measurement results of different bulks YBCO during 2001 2008, and Fig. 13 is the comparison of the levitation force relaxation measurement results of different bulks YBCO in 2001 2008. A5, old-1, 07-1, and 08-1 in the graphs represent onboard bulk YBCO in 2000, bulk YBCO of not loaded in 2000, new bulk YBCO in 2007, and in 2008, respectively. All measurement results are normalized with respect to the results of A5 all aligned along the centerline of the PMG. In Fig 12 and Fig 13, the measurenment results of the levitation force and relaxation time of the A5, 07-1, 08-1, and old-1 samples remained almost constant.

These experiment results validate the fact that the performances of the bulk YBCO samples above the PMG did not change after nearly nine years. Our research results can be applied to not only the first man-loading HTS maglev vehicle, but also to other superconducting applications such as HTS Maglev bearings and superconducting flywheel energy storage devices.

\section{Measurement system with more functions and higher precision}

(Wang S. et al., 2007)

Although the first man-loading HTS Maglev vehicle in the world (Wang J. et al., 2002) was developed successfully with the research results from the SCML-01 measurement system (Wang J. et al., 2000), the measurement functions and precision of the SCML-01 platform needed to be improved. Therefore, to make more thorough and careful investigations on the magnetic levitation properties of the HTS Maglev vehicle over a PMG, an SCML-02 HTS Maglev measurement system (Wang S. et al., 2007) with several special functions and high precision was successfully developed. 


\subsection{System description}

The SCML-02 HTS Maglev measurement system includes experiment system, control hardware and control processing software.

The experiment system is shown in Fig. 14. Four vertical support posts 1 are fixed on an optical bedplate. The upside liquid nitrogen vessel 6 with HTSCs is placed above a PM or PMG 7. The underside liquid nitrogen vessel 11 with HTS bulks is placed under a PM. In this way, the experiment system can be fit for different measurement, especially measurement of Maglev properties of superconductor samples on a PMG. The inertial force effect (tension) of movement parts is decreased by four force balance chain wheels 3 and corresponding counterweights. The $x-y$ electromotion seat is fixed onto the optical bedplate. Horizontal directions along the $\mathrm{x}$ and $\mathrm{y}$ axis can be moved together or separately. Therefore the measured HTS bulk samples can be moved in three dimensions.

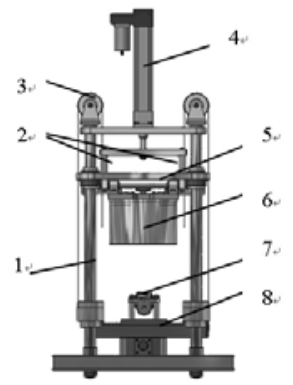

(a)

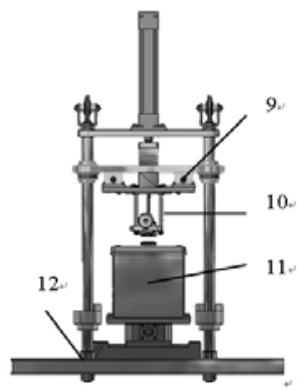

(b).

Fig. 14. The design scheme of the SCML-02 HTS Maglev measurement system: (a) Upside liquid nitrogen vessel; (b) Underside liquid nitrogen vessel.

1. Vertical support post; 2. Vertical force sensor; 3. Force balance chain wheel; 4. Servo motor; 5. Slip set; 6 . Upside liquid nitrogen vessel; 7. Underside clamp of cylinder PM or PMG; 8. XY electro-motion seat; 9. Horizontal force sensor; 10. Upside clamp of cylinder PM or PMG; 11. Underside liquid nitrogen vessel; 12. Optical bedplate.

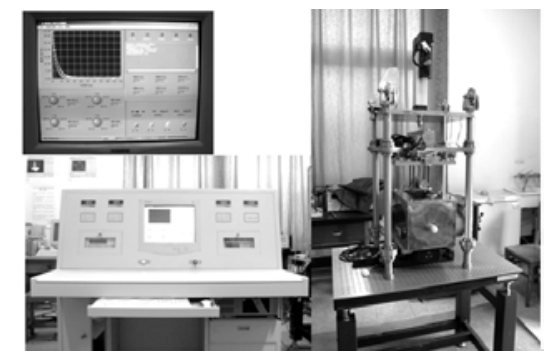

Fig. 15. Photo of the SCML-02 HTS Maglev measurement system: Levitation force measurement interface (top left corner); Console control desk (under left corner); Experiment system (right). 
The vertical levitation force and the horizontal guidance force are measured by four force sensors. The vertical sensor and the horizontal sensor are insulated from each other, and it is possible to avoid interference between the two kinds of force sensors. Therefore SCML-02 Maglev measurement system can measure the levitation force and the guidance force at the same time.

Fig. 15 shows a photograph of the SCML-02 HTS Maglev measurement system.

\subsection{The function and technical specification}

The system includes a liquid nitrogen vessel, cylindrical PM (or PMG), data collection and processing, mechanical drive and Autocontrol. The special functions of the SCML-02 Maglev measurement system can be summarized as follows:

High precision measurement;

Measurement of both a single or a number of HTS bulk samples;

1. Measured HTS bulk samples and the PM can move along the three dimensions at one time.

2. The location of the HTS bulk and PM can be interchanged;

3. Maglev properties measurement between the measured HTS bulk specimens and a cylindrical PM or a PMG;

4. Simultaneous measurement of the levitation force and guidance force for which the sample can be displaced vertically and horizontally at the same time;

5. Synchronous measurement of not just the levitation and guidance forces, but also the cross stiffness of the levitation force or the guidance force in a real-time independent measurement along the vertical or horizontal;

6. Interaction of dynamic rigidity of levitation force and guidance force synchronous measurement;

7. Relaxation time of levitation force and guidance force measurement along the vertical or horizontal directions;

The SCML-02 Maglev measurement system's main technical specification are as follows:

1. Vertical maximal displacement of $150 \mathrm{~mm}$,

2. Horizontal maximal displacement of $100 \mathrm{~mm}$;

3. Position precision of $0.05 \mathrm{~mm}$;

4. Vertical maximal support force of $1,000 \mathrm{~N}$;

5. Vertical force precision of $2 \%$;

6. Horizontal maximal support force of $500 \mathrm{~N}$;

7. Horizontal force precision of $1 \%$.

\subsection{Measurement precision calibration}

In order to calibrate the measurement precision of the SCML-02 HTS Maglev measurement system, two cylindrical PMs were used. The two PMs have the same strength and size dimensions. During the levitation force test, standard weights of $9.8 \mathrm{~N}, 18.62 \mathrm{~N}$, and $24.95 \mathrm{~N}$, and vertical moving velocities of $0.1 \mathrm{~mm} / \mathrm{s}$ to $1.0 \mathrm{~mm} / \mathrm{s}$ (velocity partition $0.1 \mathrm{~mm} / \mathrm{s}$ ) were used. Fig. 16 shows test results of the levitation force at the standard weight of $9.8 \mathrm{~N}$ and at different sampling velocities. At the standard weight of $9.8 \mathrm{~N}$, the measurement precision of 
the levitation force was $99.23 \%-99.55 \%$, and the error $0.453 \%-0.773 \%$ with the range of 0.00256-0.02924.

Thus it can be seen from Fig. 17 that the levitation force change is independent of the standard weights of $9.8 \mathrm{~N}, 18.62 \mathrm{~N}$ and $24.95 \mathrm{~N}$, as the total change was between 0.00163 0.0292 . The levitation force measurement error was found to be plus or minus $0.5 \%$.

Fig. 18 shows test results of the levitation force at different sampling velocities which justifies the good repeatability of the levitation force measurements of the SCML-02 HTS Maglev measurement system.

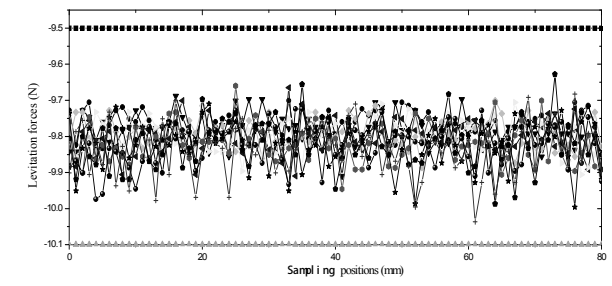

Fig. 16. Test results of the levitation force at the standard weight of $9.8 \mathrm{~N}$ at different sampling velocities (the vertical move velocities are 0.1 $\mathrm{mm} / \mathrm{s}$ to $1.0 \mathrm{~mm} / \mathrm{s}$ (velocity partition $0.1 \mathrm{~mm} / \mathrm{s}$ )

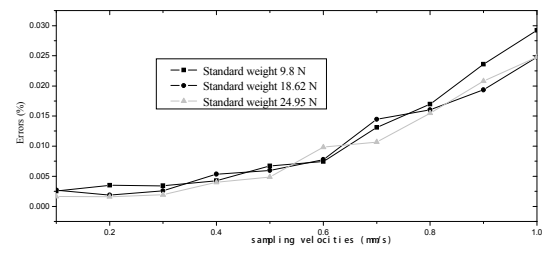

Fig. 17. Test errors of levitation forces at the different standard weight and sampling velocity

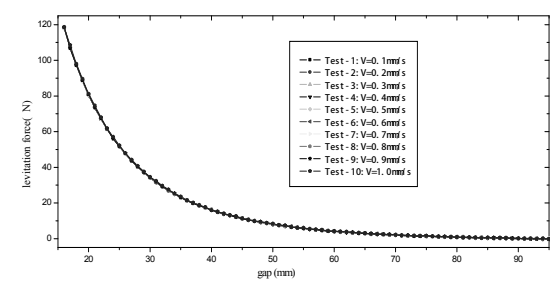

Fig. 18. Test results of levitation forces at different sampling velocities

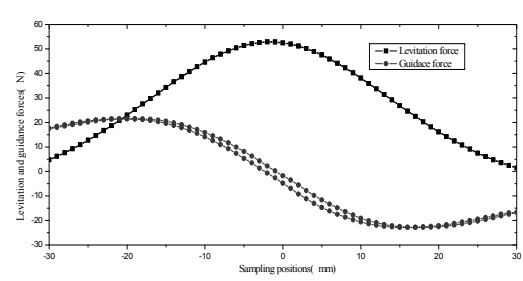

Fig. 19. Synchronous test results of the levitation forces and the guidance forces at sampling velocity of $0.5 \mathrm{~mm} / \mathrm{s}$.

Fig. 19. shows the synchronous test results of the levitation force and guidance force at the sampling velocity of $0.5 \mathrm{~mm} / \mathrm{s}$. The curves with other sampling velocities of $0.1 \mathrm{~mm} / \mathrm{s}$ to 1.0 $\mathrm{mm} / \mathrm{s}$ (velocity partition $0.1 \mathrm{~mm} / \mathrm{s}$ ) are also shown and found to fit well with the profile.

Fig. 20 shows the stiffness test results of the levitation forces at the sampling velocity of 1.0 $\mathrm{mm} / \mathrm{s}$. Sampling point gap was $1.0 \mathrm{~mm}$, and 61 sampling points were taken in the measurement range of $95-15 \mathrm{~mm}$. 


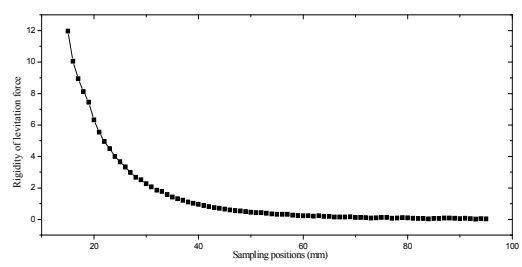

Fig. 20. Stiffness test results of the levitation forces at the sampling velocity of $1.0 \mathrm{~mm} / \mathrm{s}$.

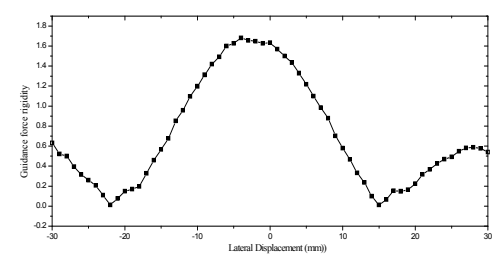

Fig. 21. Test results of levitation force at the standard weight $9.8 \mathrm{~N}$ and different sampling velocity (the vertical move velocities are 0.1 $\mathrm{mm} / \mathrm{s}$ to $1.0 \mathrm{~mm} / \mathrm{s}$ (velocity partition $0.1 \mathrm{~mm} / \mathrm{s}$ ).

Fig. 21. shows the stiffness test results of the guidance forces with the sampling velocity of $1.0 \mathrm{~mm} / \mathrm{s}$. The sampling point gap was $1.0 \mathrm{~mm}$, and 61 sampling points were taken in the measurement range of -30 to $30 \mathrm{~mm}$.

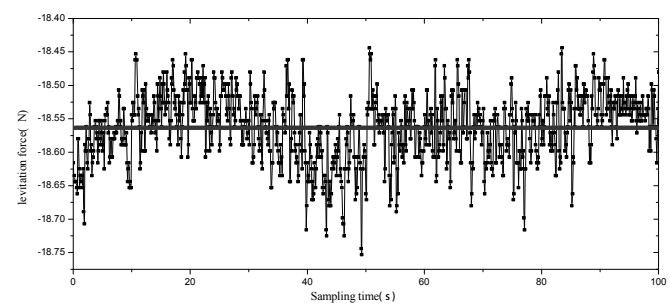

Fig. 22. Test errors of levitation forces at the different standard weight and sampling velocity.

Fig. 22. shows time-dependent levitation forces at the standard weights of $18.62 \mathrm{~N}$. The sampling point interval was $0.1 \mathrm{~s}$, and 1001 sampling points were acquired at the measurement range of 1-100 s.

The above magnetic levitation properties between the PMs were measured by the SCML-02 HTS Maglev measurement system. These measurement results validate the high precision and multi-functionality of the SCML-02.

\subsection{Measurement results of HTS Maglev properties}

The Maglev properties of YBCO bulk are measured on the basis of the above calibration results of SCML-02 HTS Maglev measurement system. The levitation forces of single YBCO bulk and an array of 7 YBCO bulks above a PMG were measured by the SCML-02 HTS Maglev measurement system. The array of $7 \mathrm{YBCO}$ bulks are concentrically arranged, where 3 bulks share one axis along the axis line of the PMG.

The diameter of the single YBCO bulk was $48 \mathrm{~mm}$, and the diameter of each of the array of 7 YBCO bulks was $30 \mathrm{~mm}$. 


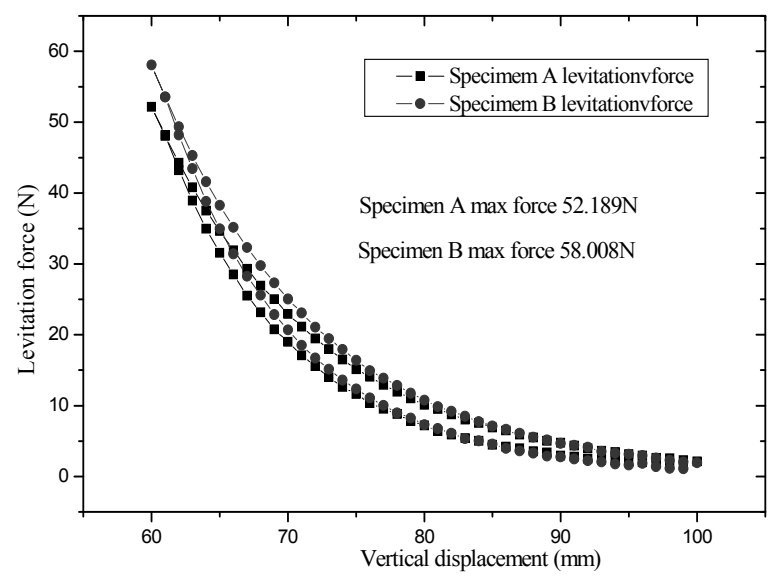

Fig. 23. Levitation forces of two YBCO bulk samples with diameter of $48 \mathrm{~mm}$ (FCH of 35 $\mathrm{mm}$, measurement range of 60-100 $\mathrm{mm}$ ).

Fig. 23. shows the measurement results of the levitation forces of two YBCO bulks with diameter of $48 \mathrm{~mm}$ with a field cooling height $(\mathrm{FCH})$ of $35 \mathrm{~mm}$ and vertical measurement ranges from 60 to $100 \mathrm{~mm}$ and backward.

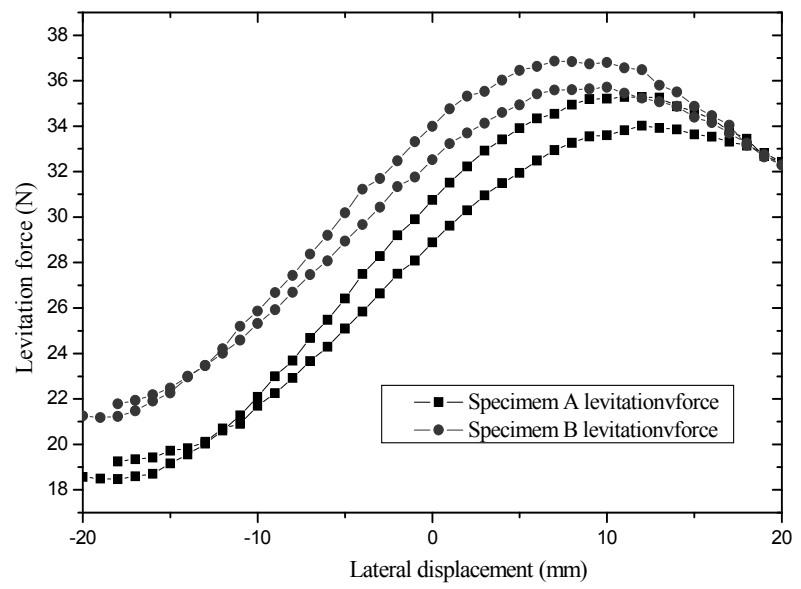

Fig. 24. Guidance forces of two YBCO bulk sample with diameter of $48 \mathrm{~mm}$ (FCH of $35 \mathrm{~mm}$, measurement height of $15 \mathrm{~mm}$,).

Fig. 24. shows the measurement results of the guidance forces along the lateral direction of the PMG. The YBCO samples had a diameter of $48 \mathrm{~mm}$, field cooling height (FCH) of $35 \mathrm{~mm}$, measurement height $(\mathrm{MH})$ of $15 \mathrm{~mm}$, and lateral displacement measurement range of -20 to $20 \mathrm{~mm}$. 


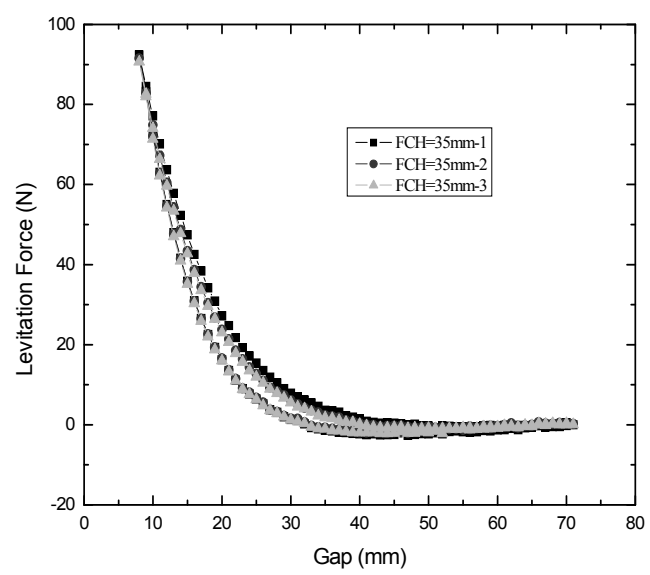

Fig. 25. Levitation forces of an array of 7 YBCO bulk samples with diameter of $30 \mathrm{~mm}$ (FCH $35 \mathrm{~mm})$.

Fig. 25. shows the measurement results of the levitation forces of three different arrangements of $7 \mathrm{YBCO}$ samples above the PMG. These 7 YBCO bulk samples had a diameter of $30 \mathrm{~mm}$ and $\mathrm{FCH}$ of $35 \mathrm{~mm}$.

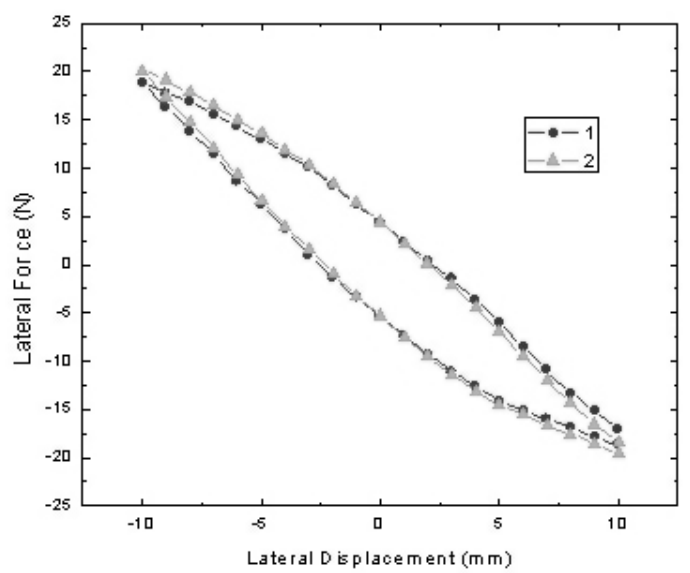

Fig. 26. Guidance forces of an array of 7 YBCO bulk samples of diameter $30 \mathrm{~mm}$ (FCH 35 $\mathrm{mm}$, measurement height $10 \mathrm{~mm}$ ).

Fig. 26. shows the measurement results of the guidance forces of three arrangements of 7 YBCO bulks above a PMG. The MH for this experiment was of $10 \mathrm{~mm}$, and the lateral measurement range from -10 to $10 \mathrm{~mm}$. 


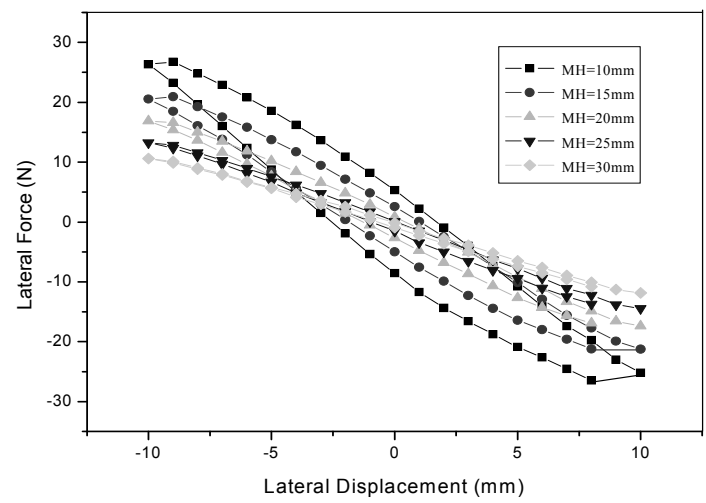

Fig. 27. The guidance forces of $7 \mathrm{YBCO}$ bulks with diameter of $30 \mathrm{~mm}$ are measured by SCML-02 (FCH of $20 \mathrm{~mm}, \mathrm{MH}$ range of $10-30 \mathrm{~mm}$, lateral measurement range of -10 to 10 $\mathrm{mm})$.

Fig. 27. shows the measurement results of the array of 7 YBCO samples above a PMG at different MHs. The $\mathrm{FCH}$ was set to $20 \mathrm{~mm}$, the measurement heights ranged from 10 to 30 $\mathrm{mm}$, and the lateral measurement ranged from -10 to $10 \mathrm{~mm}$.

The levitation forces and guidance forces of YBCO bulks are measured by SCML-02 HTS Maglev measurement system. The measurement results of HTS Maglev properties validated the accuracy and reliability of the SCML-02.

The SCML-02 measurement system can make real time measurement and the data acquisition process is controlled by a computer. The main functions and specifications of the system are unique in the world. A lot of precious experimental results were obtained from this system, like the Maglev vehicle's levitation force, guidance force and their stiffness, and cross stiffness, and so on (Deng, 2007; 2008b; 2009b; He, 2008; Jin, 2008; Liu M., 2008; Liu W., 2008; Lu, 2008; Ma, 2008; Qin, 2009; Wang J., 2005a; 2005c; 2007; 2009a; 2009b; Zheng, 2007a; $2007 b)$. All these experimental parameters are very helpful to evaluate the load capability of the HTS Maglev vehicle.

\section{HTS Maglev dynamic measurement system (Wang J. et al., 2008)}

Although the HTS Maglev measurement system SCML-02 has more functions and higher precision than SCML-01, it can not measure the running performance of bulk YBCO samples above a PMG. For the further engineering application of the HTS Maglev vehicle, the dynamic properties of the Maglev must be clearly understood. From this viewpoint, an HTS Maglev dynamic test system (SCML-03) has been designed and successfully developed in Applied Superconductivity Laboratory (ASCLab) of Southwest Jiaotong University, P. R. China (Wang J. et al., 2008). The test process and results of the HTS Maglev dynamic test system are reported in this section. 


\subsection{System description}

When the HTS Maglev vehicle runs along the PMG, it is difficult to measure its dynamic properties. In SCML-03, the rotational motion of a circular PMG instead of the physical motion of thea YBCO bulk was taken to be the equivalent measure of the dynamic interaction between the superconductor and the PMG. That is, the circular PMG can rotate to different speeds while the onboard HTS Maglev equipment is fixed above the PMG and this will simulate the fact that the superconductor is traveling above a PMG. SCML-03 is composed of a vertical load, horizontal load, three-dimensional measurement systems, liquid nitrogen vessel, circular PMG, drive device, data acquisition and processing, autocontrol, and so on.

The main measurement functions include the dynamic stability of the HTS Maglev equipment (liquid nitrogen vessel including the HTS samples), the levitation force and guidance force of both single and multi HTS bulk samples, the levitation force and guidance force rigidity of both single and multi HTS bulk samples, the levitation force and guidance force change at the levitation gap, and so on.

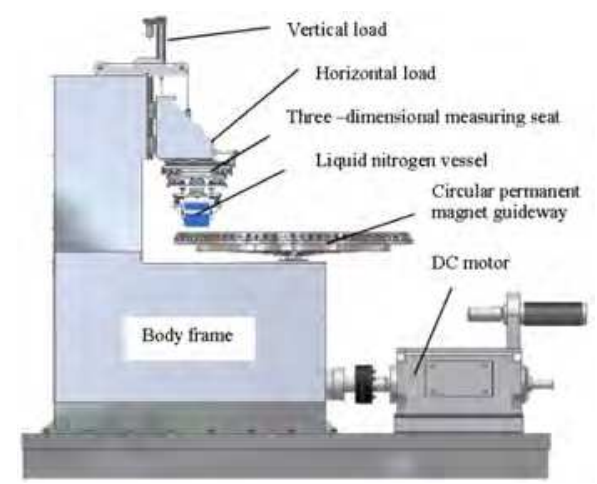

Fig. 28. The design scheme and principal parts of the HTS Maglev dynamic test system SCML-03 (not including power supply and measurement control desk)

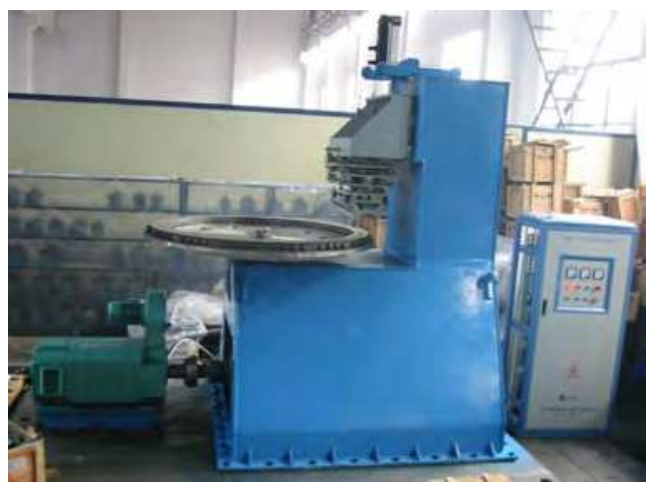

Fig. 29. The photo of the airframe of the HTS Maglev dynamic test system SCML-03: $3.3 \mathrm{~m}$ long, $2.4 \mathrm{~m}$ wide and $3.15 \mathrm{~m}$ high With a total weight of $13.95 \mathrm{t}$ 


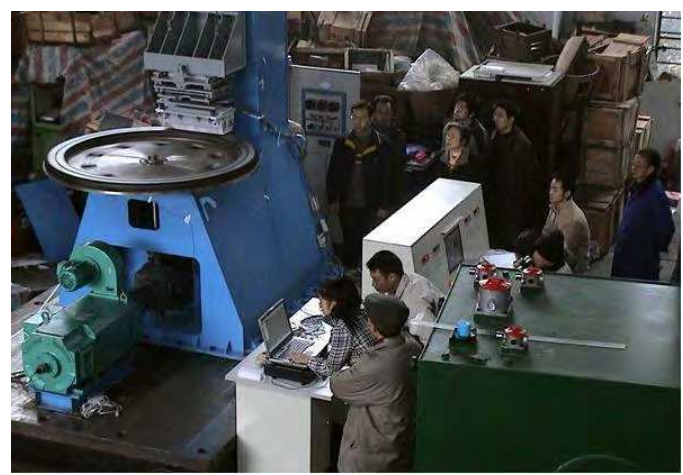

Fig. 30. The measurement scene of the HTS Maglev dynamic test system.

On the right side is the control desk

The main part design scheme of SCML-03 is shown in Fig. 28. The airframe of the HTS Maglev dynamic test system SCML-03 (not including the measurement control desk) is shown in Fig. 29. The total technical parameters of the principal part of the SCML-03 are 3.3 $\mathrm{m}$ long, $2.4 \mathrm{~m}$ wide and $3.15 \mathrm{~m}$ high. The total weight is $13.95 \mathrm{t}$ which includes the circular PMG disk that weights $0.6 \mathrm{t}$. Fig. 30 shows the measurement scene of the HTS Maglev dynamic test system, the control desk is on the bottom right.

A DC motor is used to drive the circular PMG to rotate and control its rotational speed. The rotational direction of the DC motor is translated into the horizontal rotation direction of the circular PMG by a gear redirection case. The circular PMG is fixed along the circumferential direction of a big circular disk with a diameter of $1,500 \mathrm{~mm}$. The rotating unbalance of the big circular disk is less than $20 \mathrm{gm}$. The maximum linear velocity of the PMG is about 300 $\mathrm{km} / \mathrm{h}$ when the circular disk rotates round the central axis at 1,280 rpm. The rotation speed error of the circular disk is less than $3 \%$.

The three-dimensional measuring seat is fixed on the horizontal load. The seat can be moved along the horizontal direction which is perpendicular to the tangential direction of the circular PMG. Therefore, the HTS Maglev dynamic guidance force can be measured at the same time. Six force sensors are used to measure the vertical, transverse, and longitudinal directional forces of the liquid nitrogen vessel. In order to measure the threedimensional dynamic response, the liquid nitrogen vessel is connected to the threedimensional measuring seat by elastomers.

The autocontrol of all components are completed by the total control desk. Both measurement and control software was developed on basis of Labview software by National Instruments. The servo motor movement and the circular PMG speed are controlled by both the software program and relative control card.

In order to calibrate measurement precision of the dynamic measurement system, 11 channel Noise \& Vibration Measurement System made by B \& K was used. The dynamic vertical levitation force is measured when the circular PMG is rotated by different speed. 


\subsection{The functions and technical specifications}

The SCML-03 can measure the dynamic properties in opposite motion between the vehicle and the PMG. The main measurement functions include:

1. Dynamic stability measurement of the HTS Maglev equipment (liquid nitrogen vessel included HTS bulks ) at different velocities;

2. Measurement of levitation force and guidance force of both single and multi HTS bulk samples;

3. Measurement of levitation force stiffness and guidance force stiffness of both single and multi HTS bulk samples;

4. Measurement of levitation force and guidance force change at different levitation gap clearances;

Main technical specifications:

1. Diameter of the circular PMG 1,500 mm;

2. Maximal linear speed of the circular PMG $300 \mathrm{~km} / \mathrm{h}$;

3. Rotation speed precision of the circular PMG $\pm 3 \%$;

4. Vertical maximal displacement $200 \mathrm{~mm}$;

5. Horizontal maximal displacement $\pm 50 \mathrm{~mm}$;

6. Position precision $\pm 0.05 \mathrm{~mm}$;

7. Vertical maximal support force $3,350 \mathrm{~N}$;

8. Horizontal maximal support force $500 \mathrm{~N}$;

9. Force sensor precision $\pm 1 \%$.

\subsection{Stability of dynamic test system}

The most important propertiy of the dynamic test system is its self stability. The rotating unbalance of the PMG circular disk was measured to be less than $20 \mathrm{gm}$. The rotating unbalance value satisfies the system measurement's needs. The other important parameter of the dynamic test system is the self stability of the liquid nitrogen vessel and the body frame. In order to confirm the self stability, a 11 channel Noise \& Vibration Measurement System was used. A 4507-004B accelerometer was fixed onto the body frame, and four 4507004B accelerometers were fixed on the clamp device of the liquid nitrogen vessel. The vibrations of the perpendicular and horizontal directions on the clamp device were measured by two sensors. A picture of the measurement scene of the SCML-03 is shown in Fig. 30.

The vibration spectrums of the body frame and the clamp device of the liquid nitrogen vessel were measured at the rotation speeds of $50 \mathrm{rpm}, 100 \mathrm{rpm}, 200 \mathrm{rpm}, 300 \mathrm{rpm}$, and 400 $\mathrm{rpm}$. The vibration spectrum of the clamp device of the liquid nitrogen vessel includes both the perpendicular direction and the horizontal direction. The vibration spectrum of the body frame at $400 \mathrm{rpm}$ is shown in Fig. 31. The vibration spectrums of the perpendicular direction and the horizontal direction on the liquid nitrogen vessel at $400 \mathrm{rpm}$ are shown in Fig. 32 and Fig. 33. 
Fig. 31. Vibration spectrum of the body frame at $400 \mathrm{rpm}$
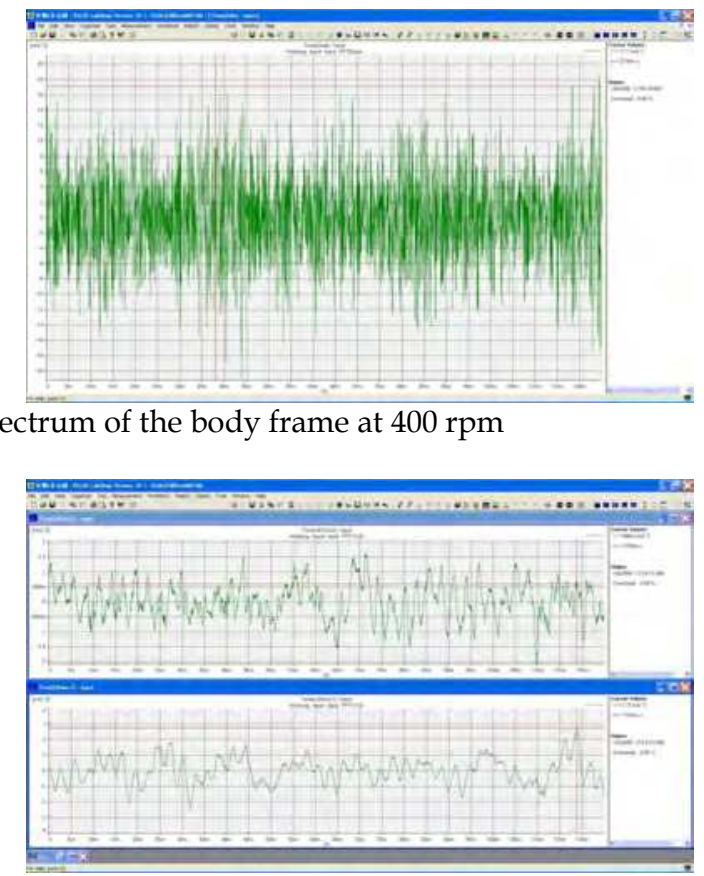

Fig. 32. Vibration spectrum along the perpendicular direction on the clamp device of the liquid nitrogen vessel at $400 \mathrm{rpm}$.

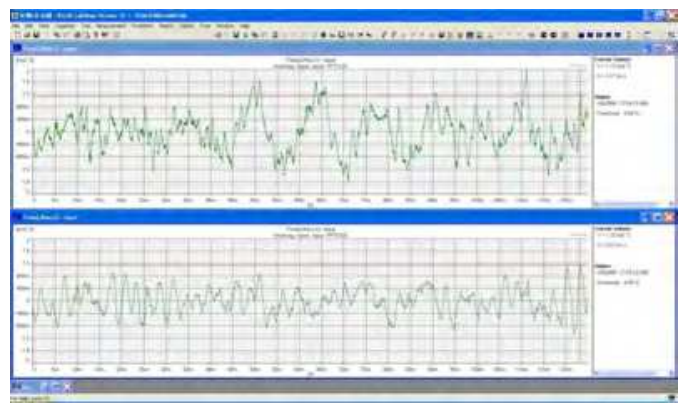

Fig. 33. Vibration spectrum along the horizontal direction on the clamp device of the liquid nitrogen vessel at $400 \mathrm{rpm}$.

Fig. 34. shows the vibration measuring results of the body frame and the clamp device of the liquid nitrogen vessel (the perpendicular and the horizontal direction) at the rotation speed of $50 \mathrm{rpm}, 100 \mathrm{rpm}, 200 \mathrm{rpm}, 300 \mathrm{rpm}$, and $400 \mathrm{rpm}$. The left figure shows the measuring vibration results without the liquid nitrogen vessel on the clamp device. The right figure shows results with the liquid nitrogen vessel attached. After the YBCO superconductors in the vessel are cooled in the zero field, vibration properties are measured at the levitation gap of $20 \mathrm{~mm}$ and the lateral displacement of $0 \mathrm{~mm}$. Experimental results show that the 
vibration of the body frame increases quickly with the increase of rotation speed, and the vibration of the clamp device with or without the liquid nitrogen vessel also increases slowly with the increase of rotation speed. This indicates that the measuring seat has the function of vibration isolation. The vibration of the clamp device with the liquid nitrogen vessel satisfies measurement requirements.

\subsection{Measurement of HTS Maglev properties}

The main distinguish between the SCML-03 and previous HTS Maglev measurement system (Wang J. et al., 2000; Wang S. et al., 2007) is to measure the Maglev performance at the running case. By SCML-03, both levitation forces and guidance forces are measured experimentally at different velocities.

The experimental results of the levitation forces and the guidance forces of YBCO bulk measured with the SCML-03 are shown in Fig. 35 and Fig. 36, respectively. The levitation forces of YBCO bulk were measured in zero field cooling (ZFC), and the guidance forces of YBCO bulk were measured at $15 \mathrm{~mm}$ field cooling height. Those measurement results verified that the SCML-03 is applicable for measurement of the levitation and the guidance forces at movement state.

In order to prove the applicability of the measurement results of the levitation forces and the guidance forces of YBCO bulks, the changes of the measurement results with different
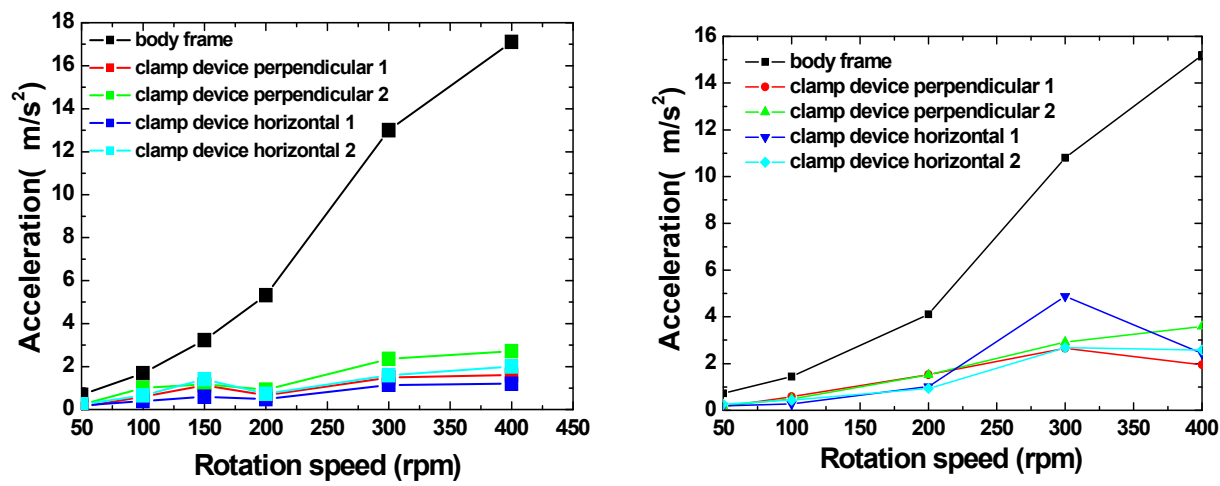

Fig. 34. Vibration measuring results of the body frame and the clamp device of the liquid nitrogen vessel (perpendicular and horizontal direction) at rotation speeds of $50 \mathrm{rpm}, 100$ rpm, $150 \mathrm{rpm}, 200 \mathrm{rpm}, 300 \mathrm{rpm}$, and $400 \mathrm{rpm}$. Left (right) figure shows the measuring results without (with) the liquid nitrogen vessel on the clamp device. 


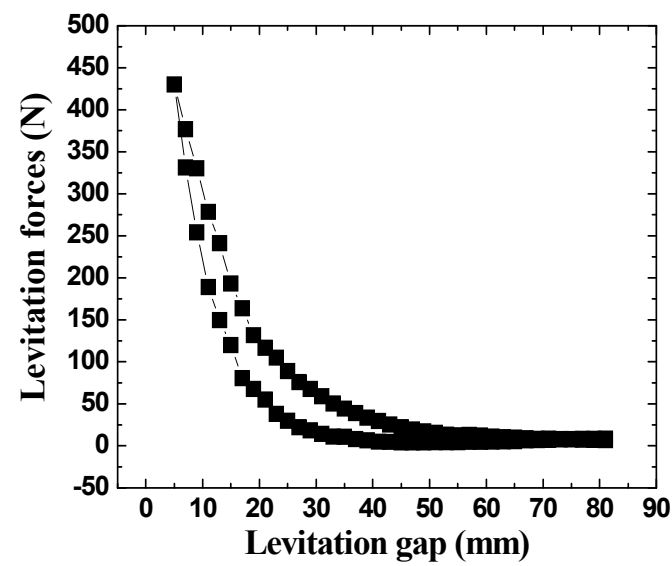

Fig. 35. Measurement results of the levitation forces of YBCO bulk in zero field cooling (ZFL).

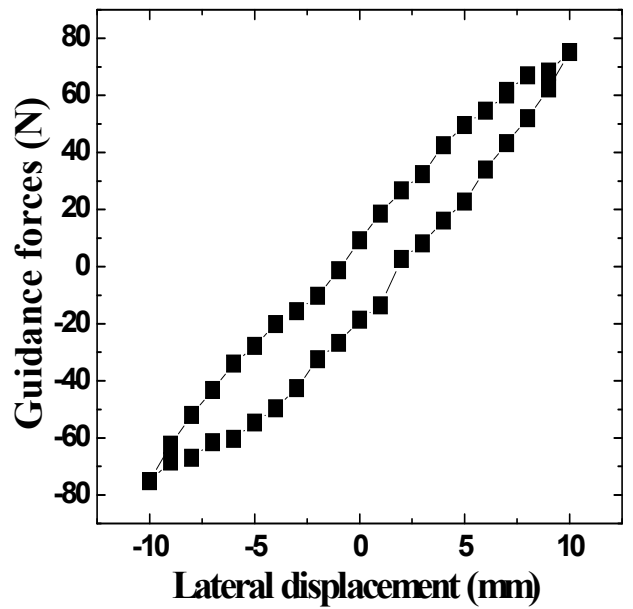

Fig. 36. Measurement results of the guidance forces of YBCO bulk at a $15 \mathrm{~mm}$ levitation gap for the field cooling (FL).

measuring time and different rotational speeds were investigated experimentally. Rotational speeds of $50 \mathrm{rpm}, 100 \mathrm{rpm}, 200 \mathrm{rpm}, 300 \mathrm{rpm}$, and $400 \mathrm{rpm}$, with time intervals of $12 \mathrm{~s}$ were tested and shown in Fig. 37. The experimental results are measured at the levitation gap of $10 \mathrm{~mm}$.

Fig. 37. shows that the changes of the measured levitation forces are small, especially at the $300 \mathrm{rpm}$ and $400 \mathrm{rpm}$ speeds. The higher the PMG rotation speed, the smaller the levitation force changes. At the levitation gap of $10 \mathrm{~mm}$ the changes found on the measured levitation forces in a $48 \mathrm{~s}$ period were $0.54 \mathrm{~N}$ at $300 \mathrm{rpm}$ and $0.10 \mathrm{~N}$ at $400 \mathrm{rpm}$. 

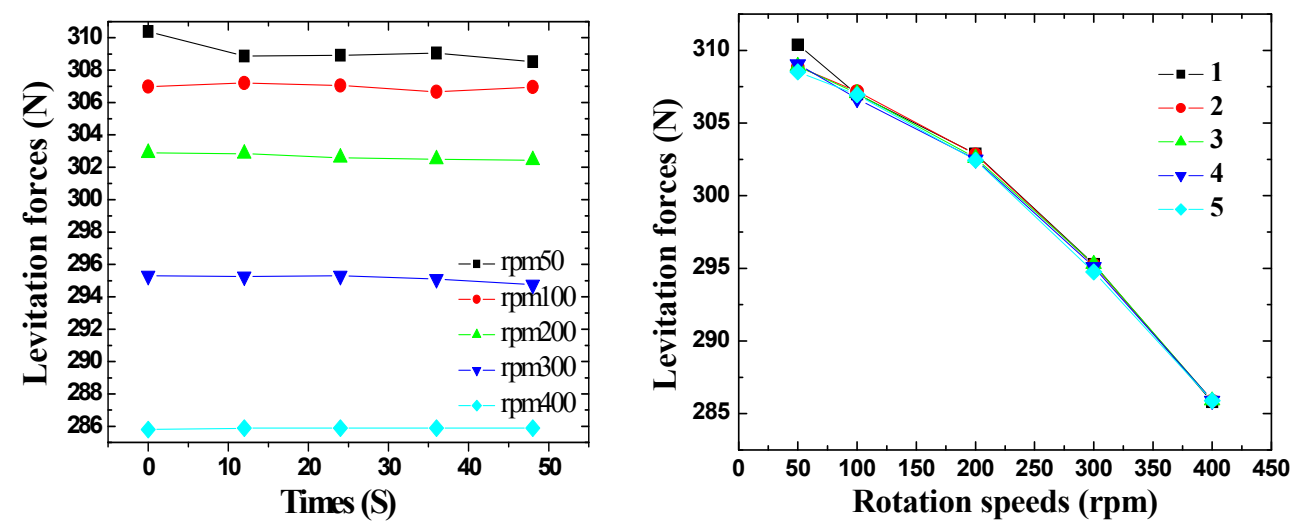

Fig. 37. Experimental results of the levitation force of zero field cooling YBCO superconductor bulks at time intervals of $12 \mathrm{~s}$ and special rotation speed (the levitation gap of $10 \mathrm{~mm}$ ).

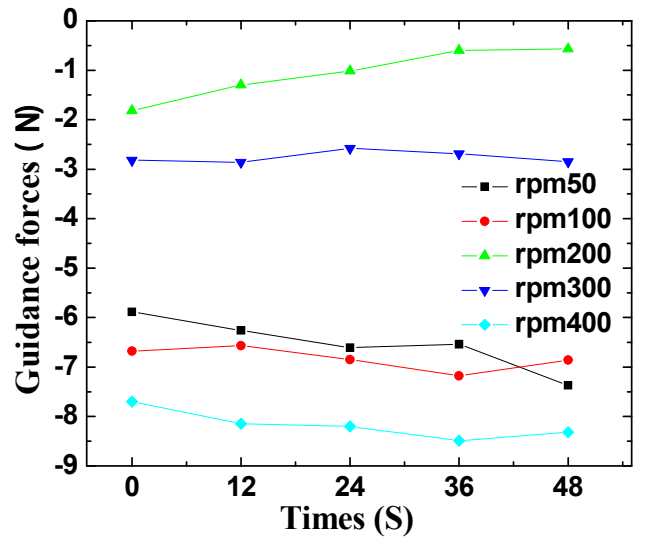

Fig. 38. Experimental results of the guidance force of field cooling YBCO bulks at time intervals of $12 \mathrm{~s}$, levitation gap was of $15 \mathrm{~mm}$, and special rotation speed.

The levitation force decreases with the increase of rotational speed. The decrease in value of the levitation forces is $22.98 \mathrm{~N}$ when the rotation speed is increased from $50 \mathrm{rpm}$ to $400 \mathrm{rpm}$ at time intervals of $12 \mathrm{~s}$, which is a decrease of the levitation forces of $7.4 \%$ from the original value. The reason for decreasing of the levitation forces can be attributed to some subtle changes in the uniformity of the circular PMG's magnet field along the circumferential direction which at high speeds is equivalent subjecting the HTS to an AC magnetic field.

The experimental results of the guidance force of field cooling YBCO superconductor bulks at the time intervals of $12 \mathrm{~s}$, levitation gap of $15 \mathrm{~mm}$, and special rotation speed are shown in Fig. 38. It indicates that the changes of measured guidance forces at the time intervals of $12 \mathrm{~s}$ are small, especially at $300 \mathrm{rpm}$ and $400 \mathrm{rpm}$. The higher PMG rotation speed, the smaller 
the guidance force changes. The experimental results of the guidance forces are not better than that of the levitation forces. The most changes of measured guidance forces in the $48 \mathrm{~s}$ time frame were $0.28 \mathrm{~N}$ at $300 \mathrm{rpm}$ and $0.79 \mathrm{~N}$ at $400 \mathrm{rpm}$ ).

\section{Conclusion}

Three high temperature superconducting (HTS) Maglev measurement systems were successfully developed in the Applied Superconductivity Laboratory (ASCLab) of Southwest Jiaotong University, P. R. China. These systems include liquid nitrogen vessel, Permanent Magnet Guideway (PMG), data collection and processing, mechanical drive and Autocontrol features. This chapter described the three different measuring systems along with their theory of operations and workflow.

The SCML-01 HTS Maglev measurement system can make real time measurement of Maglev properties between one or many YBCO bulks and employ a PM or PMG. Also the trapping flux of high $T_{\mathrm{c}}$ superconductors can be measured in the scanning range of 100 $\mathrm{mm} \times 100 \mathrm{~mm}$. It was especially employed to develop the on board HTS Maglev equipment which travels over one or two PMGs. The on board Maglev equipment includes a rectangular-shaped liquid nitrogen vessel and YBCO bulk superconductors. Based on the original research results from the SCML-01, the first man-loading HTS Maglev test vehicle in the world was successfully developed in 2000.

In order to make more thorough and careful research investigations, the HTS Maglev, HTS Maglev Measurement System (SCML-02) was subsequently developed with even more function capabilities and a higher precision to extensively investigate the Maglev properties of YBCO bulk samples over a PM or PMG. The new features included: higher measurement precision, instant measurement at movement of the measured HTS sample, automatic measurement of both levitation and guidance forces, dynamic rigidity, ability for the measured HTS sample to be moved along the three principal axes all at once, relaxation measurements of both levitation and guidance forces, and so on. The main specification of the system is: position precision $\pm 0.05 \mathrm{~mm}$. vertical force precision $2 \%$; horizontal force precision $1 \%$; and force measurement precision of $0.02 \mathrm{~N}$.

In order to investigate the dynamic characteristics behavior of the HTS Maglev engineering application, an HTS Maglev dynamic measurement system (SCML-03) was designed and successfully developed. The circular PMG is fixed along the circumferential direction of a big circular disk with a diameter of $1,500 \mathrm{~mm}$. The maximum linear velocity of the PMG is about $300 \mathrm{~km} / \mathrm{h}$ when the circular disk rotates round the central axis at $1280 \mathrm{rpm}$. The liquid nitrogen vessel with HTS bulks is placed above the PMG, and the vessel is allowed to move along the three main principal axes so that sensors can detect force variations stemming from the superconductors.

The design, method, accuracy and results have allowed the successful development of these three measurement systems. All systems are calibrated by standard measurement technology, for which its reliability, stability, featured functions, and precision have also been validated through its long-term usage. 


\section{Acknowledgements}

The authors are grateful to Zhongyou Ren, Yiyu Lu, Zigang Deng, Jun Zheng, Fei Yen, Changyan Deng, Youwen Zeng, Haiyu Huang, Xiaorong Wang, Honghai Song, Xingzhi Wang, Longcai Zhang, Hua Jing, Qingyong He, Lu Liu, Guangtong Ma, Wei Liu, Qunxu Lin, Yonggang Huang, Minxian Liu, Yujie Qing, Rongqing Zhao, and Ya Zhang for their contributions towards the abovementioned HTS Maglev measurement systems.

\section{References}

Bomemann H. J., A. Tonoli, T. Ritter, C. Urban, O. Zaitsev, K. Weber, and H. Rietschel, (1995). Engineering Prototype of a Superconducting Flywheel for Long Term Energy Storage. IEEE Trans. Appl. Supercond., 5(2): 618-621

D' Ovidio G., F. Crisia, G. Lanzara, (2008). A 'V' shaped superconducting levitation module for lift and guidance of a magnetic transportation system. Physica C, vol 468, pp. 1036-1040

Deng Zigang, Jun Zheng, Honghai Song, Lu Liu, Lulin Wang, Ya Zhang, Suyu Wang, and Jiasu Wang, (2007). Free Vibration of the High Temperature Supercond. Maglev Vehicle model. IEEE Trans Appl Supercond, 17(2): 2071-2074

Deng Zigang, Wang Jiasu, Wang Suyu, Zheng Jun, Ma Guangtong, Lin Qunxu, Zhang Ya, (2008a). Status of High Temperature Supercond. Flywheel Energy Storage System. Transactions of China Electrotechnical Society, 23(12): 1-10 (In chinese)

Deng Z., J. Wang, J. Zheng, H. Jing, Y. Lu, G. Ma, L. Liu, W. Liu, Y. Zhang, S. Wang, (2008b). High-efficiency and low-cost permanent magnet guideway consideration for highTc superconducting Maglev vehicle practical application. Superconductor Science and Technology, 21(11): 115018 (9pp)

Deng Zigang, Wang Jiasu, Wang Suyu, Zheng Jun, Lin Qunxu, Zhang Ya, (2009)a. R \& D Status of High-Tc Superconducting Magnetic Bearings. Transactions of China Electrotechnical Society, (In chinese)

Deng Z., Q. Lin, J. Wang, J. Zheng, G. Ma, Y. Zhang, S. Wang, (2009b). Basic design and characteristics study of a double-axial superconducting magnetic bearing system. Cryogenics, doi: 10.1016/j. Cryogenics, 10.006

He Qingyong, Jiasu Wang, Longcai Zhang, Suyu Wang and Siting Pan, (2008). Influence of the Ramp Angle on Levitation Characteristics of HTS Maglev. Physica C, 468(1): 1216

Hellman F., E. M. Gyorgy, D. W. Johnson, Jr., H. M. O’Bryan, and R. C. Sherwood, (1988). Levitation of a magnet over a flat type II superconductor. J. Appl. Phys., vol. 63, pp. $447-450$

Honghai Song, Jiasu Wang, Suyu Wang, Zhongyou Ren, Xiaorong Wang, Oliver de Haas, Gunter Fuchs, Ludwig Schultz, (2006). Studies of YBCO Electromagnetic Properties for High-Temperature Superconductor Maglev Technology. In: Barry P. Martins Ed., New Topics in Superconductivity Research (Nova Science Publishers, Inc.) pp. $107-156$

Hull J. R., (2000). Superconducting bearings. Supercond. Sci. Technol. 13(2): R1-R15

Jing Hua, Suyu Wang, Wei Liu, Ming Jiang, Changyan Deng, Jun Zheng, Zigang Deng, Jiasu 
Wang, (2008). A high-Tc superconducting Maglev system using T-shaped permanent magnet single-guideway. IEEE Trans Appl Supercond, 18(2): 795-798

Kovalev K. L., S. M.-A. Koneev, V. N. Poltavec, et al., (2005). Magnetically levitated Highspeed carriages on the basis of bulk HTS elements," in Pro. 8th Intern. Symp. Magn. Susp. Technol. (ISMST'8), Dresden, Germany, pp. 51-

Liu Minxian, Suyu Wang, Jiasu Wang, Guangtong Ma, (2008). Influence of the Air Gap between Adjacent Permanent Magnets on the Performance of NdFeB Guideway for HTS Maglev System. Journal of Superconductivity and Novel Magnetism, 21(7): 431-435

Liu W., J.S. Wang, H. Jing, M. Jiang, J. Zheng, S.Y. Wang, (2008). Levitation performance of high-Tc superconductor in sinusoidal guideway magnetic field. Physica C, 468(23): 2345-2350

Liu wei, wang su-yu, lin qun-xu, yang pei, liu hui-fen, ma guang-tong, zheng jun, and wang jia-su, (2009). Research on the long-term operation stability of the bulk YBCO on vehicle. 10th Superdongductivity Conference of China, beijing, 2009 (In chinese)

Lu Yiyun, Jiasu Wang, Suyu Wang, Jun Zheng, (2008). 3D-Modeling Numerical Solutions of Electromagnetic Behavior of HTSC Bulk above Permanent Magnetic Guideway. Journal of Superconductivity and Novel Magnetism, 21(8): 467-472

Ma G T, Q X Lin, J S Wang, S Y Wang, Z G Deng, Y Y Lu, M X Liu, J Zheng, (2008). Method to reduce levitation force decay of the bulk HTSC above the NdFeB guideway due to lateral movement. Supercond. Sci. Technol., 21(6): 065020

Ma K B, Postrekhin Y V, Chu W K, (2003). Superconductor and magnet levitation devices. Rev. Sci. Instrum., 74(12): 4989-5017.

Moon F C. Superconducting Levitation. New York: John Wiley and Sons, 1994

Moon F. C., P. -Z. Chang, (1990). High-speed rotation of magnets on high Tc superconducting bearings. Appl. Phys. Lett., 56(4): 397-399

Okano M., T. Iwamoto, M. Furuse, S. Fuchino, I. Ishii, (2006). Running performance of a pinning-type superconducting magnetic levitation guide. J. Phys. Conf. Ser., vol. 43, pp. 999-1002

Peters P. N., R.C.Sisk, E.W.Urban, C.Y.Huang, and M.K.Wu, (1988). $\square$ 文名. Appl. Phys. Lett. 52: 2066

Qin Yujie, Yiyun Lu, Suyu Wang, Jiasu Wang, (2009). Levitation Force Relaxation of HTS Bulk above NdFeB Guideways at Different Approaching Speeds. Journal of Superconductivity and Novel Magnetism, 22(5): 511-516

Ren Zhongyou, Jiasu Wang, Suyu Wang, He Jiang, Min Zhu, Xiaorong Wang, Honghai Song, (2003). Influence of shape and thickness on the levitation force of $\mathrm{YBaCuO}$ bulk HTS over a NdFeB guideway. Physica C, 384(1-2): 159-162

Schultz L., O de Haas, P. verges, C. Beyer, S. Rohlig, H. Olsen, et al., (2005). Superconductively levitated transport system-the SupraTrans project. IEEE Trans Appl. Supercond., vol. 15, 2301-2305

Song H.H., O. De Haas, Z.Y. Ren, X.R. Wang, et al., (2004). Magnetic interaction between multiple seeded YBCO bulks and the permanent magnet guideway. Physica $C$, 407(1-2): 82-87

Stephan R. M., A. C. Ferreira, R. de Andrade, Jr. M. A. Neves, M. A. Cruzmoreira, M. A. P. Rosario, et al., (2004). A superconducting levitated small scale vehicle with linear synchronous motor. in 2003 IEEE Intern. Sym. Indust. Electro., vol. 1, pp. 206-209 
Wang Jiasu, Suyu Wang, Guobin Lin, Haiyu Huang, Cuifang Zhang, Youwen Zeng, Shaohua Wang, Changyan Deng, Zhipei Xu, Qixue Tang, Zhongyou Ren, He Jiang, Min Zhu, (2000). High $T_{\mathrm{c}}$ Superconducting Magnetic Levitation Measurement System, High Technology Letters, vol. 10 no. 8, pp. 56-58, (In Chinese)

Wang Jiasu, Suyu Wang, Zhongyou Ren, Min Zhu, He Jiang, and Qixue Tang, (2001). IEEE Trans. on Applied Superconductivity, 11 1801-1804

Wang Jiasu, Wang Suyu, Zeng Youwen, Huang Haiyu, Luo Fang, Xu Zhipei, Tang Qixue, Lin Guobin, Zhang Cuifang, Ren Zhongyou, Zhao Guomin, Zhu Degui, Wang Shaohua, Jiang He, Zhu Min, Deng Changyan, Hu Pengfei, Li Chaoyong, Liu Fang, Lian Jisan, Wang Xiaorong, Wang Lianghui, Shen Xuming, Dong Xiaogang, (2002). The first man-loading high temperature superconducting maglev test vehicle in the world. Physica C, 378-381: 809-814

Wang J.S., S.Y. Wang, Z.Y. Ren, H. Jiang, M. Zhu, X.R. Wang, X.M. Shen, H.H. Song. (2003a). Experiment results of high temperature superconducting maglev vehicle. Physica $C$, 386: $431-437$

Wang Jiasu, Suyu Wang, Zhongyou Ren, Xiaorong Wang, Min Zhu, He Jiang, Honghai Song, Xingzhi Wang, Jun Zheng, (2003b). Guidance Forces on High Temperature Superconducting Maglev Test Vehicle. IEEE Transactions on Applied Superconductivity, 13 (2): 2154-2156

Wang Jiasu and Wang Suyu, (2005a). Synthesis of Bulk Superconductors and Their Properties on Permanent Magnet Guideway. In: Anant Narlikar Ed., Frontiers in Superconducting Materials (Springer Verlag, Germany), pp.885-912

Wang Jiasu, Suyu Wang, Changyan Deng, Youwen Zeng, Honghai Song, Jun Zheng, Xinzhi Wang, Haiyu Huang, and Fu Li, (2005b). Design consideration of a high temperature superconductor Maglev vehicle system. IEEE Transactions on Applied Superconductivity, 15(2): 2273-2276

Wang J.S., S.Y. Wang, et al. (2005c). The present status of HTS Maglev vehicle in China. Supercond. Sci. Technol., 18: S215-S218

Wang Jiasu, Suyu Wang, Changyan Deng, Jun Zheng, Honghai Song, Qingyong He, Youwen Zeng, Zigang Deng, et al., (2007). Laboratory-scale high temperature superconducting Maglev launch system. IEEE Trans Appl. Supercond., 17(2): 20912094

Wang Jiasu, Suyu Wang, Changyan Deng, Youwen Zeng, Longcai Zhang, Zigang Deng, Jun Zheng, Lu Liu, Yiyun Lu, Minxian Liu, Yaohui Lu, Yonggang Huang, and Ya Zhang, (2008). A High-Temperature Superconducting Maglev Dynamic Measurement System. IEEE Trans Appl. Supercond., 18(2): 791-794

Wang Jiasu, Suyu Wang, Jun Zheng, (2009a). Recent development of high temperature superconducting Maglev system in China. IEEE Trans Appl. Supercond., 2009, 19(3): 2142-2147

Wang Jia-Su, Wang Su-yu, Zheng Jun, Deng Zi-Gang, Lu Yi-Yun, Ma Guang-Tong, Zhang Ya, Yen Fei, (2009b). Recent developments of high temperature superconducting maglev system. 10 th Superdongductivity Conference of China, beijing, 2009 (In chinese)

Wang Suyu, Jiasu Wang, Zhongyou Ren, Min Zhu, He Jiang, Qixue Tang, (2001a). Combination levitation force of multi-block $\mathrm{YbaCuO}$ bulk high temperature superconductors, IEEE Trans. Appl. Superconduct., vol.11, no.2, pp. 1808-1811, 
Wang Suyu, Qixue Tang, Zhongyou Ren, Min Zhu, He Jing, Jiasu Wang, (2001b). Design of high $T_{\mathrm{c}}$ superconducting Maglev system for vehicles, Superconductivity and Cryogenics, vol. 29, no. 1, pp. 14-17 (In Chinese)

Wang S.Y., J.S. Wang, Z.Y. Ren, M. Zhu, H. Jiang, X.R. Wang, X.M. Shen, H.H. Song, (2002). High temperature superconducting maglev equipment on vehicle, presented at Superconductors for Practical Applications (SPA'2002), Xi'an, P. R. China, June 16-20,

Wang S.Y., J.S. Wang, Z.Y. Ren, M. Zhu, H. Jiang, X.R. Wang, X.M. Shen, H.H. Song, (2003). High temperature superconducting maglev equipment on vehicle. Physica $C, 386$ : 531-535

Wang Suyu, Jiasu Wang, Changyan Deng, Yiyu Lu, Youwen Zeng, Honghai Song, Haiyu Huang, Hua Jing, Yonggang Huang, Jun Zheng, Xingzhi Wang, and Ya Zhang, (2007). An update High-Temperature Superconducting Maglev Measurement System. IEEE Trans Appl Supercond, 17(2): 2067-2070

Wang X.R., H.H. Song, Z.Y. Ren, M. Zhu, J.S. Wang, S.Y. Wang, X.Z. Wang, (2003). Levitation force and guidance force of $\mathrm{YBaCuO}$ bulk in applied field. Physica $\mathrm{C}$, 386: 536-539

Wang Xiaorong, Zhongyou Ren, Honghai Song, Xingzhi Wang, Jun Zheng, et al., (2005). Guidance force in an infinitely long superconductor and permanent magnetic guideway system. Supercond. Sci. Technol., 18: S99-S104

Zhang Longcai, Jiasu Wang, Suyu Wang, Qingyong He, (2007). Influence of AC external magnetic field perturbation on the guidance force of HTS bulk over a NdFeB guideway. Physica C, 459(1-2): 43-46

Zheng J., Z. Deng, S. Wang, J. Wang, Y. Zhang, (2007a). Vibration properties dependence on the trapped flux of bulk high-temperature superconductor. Physica C, 463-465: 1356-1360

Zheng Jun, Zigang Deng, Lulin Wang, Lu Liu, Ya Zhang, Suyu Wang, and Jiasu Wang, (2007b). Stability of the Maglev vehicle model using bulk high $T_{\mathrm{c}}$ superconductors at low speed. IEEE Trans Appl Supercond, 17(2): 2103-2106 


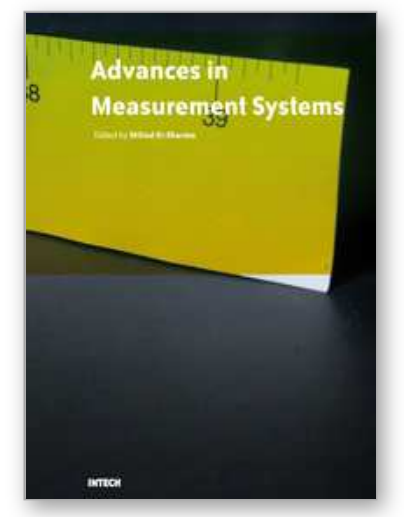

\section{Advances in Measurement Systems}

Edited by Milind Kr Sharma

ISBN 978-953-307-061-2

Hard cover, 592 pages

Publisher InTech

Published online 01, April, 2010

Published in print edition April, 2010

\section{How to reference}

In order to correctly reference this scholarly work, feel free to copy and paste the following:

Jia-Su Wang and Su-Yu Wang (2010). High Temperature Superconducting Maglev Measurement System, Advances in Measurement Systems, Milind Kr Sharma (Ed.), ISBN: 978-953-307-061-2, InTech, Available from: http://www.intechopen.com/books/advances-in-measurement-systems/high-temperaturesuperconducting-maglev-measurement-system

\section{INTECH}

open science | open minds

\section{InTech Europe}

University Campus STeP Ri

Slavka Krautzeka 83/A

51000 Rijeka, Croatia

Phone: +385 (51) 770447

Fax: +385 (51) 686166

www.intechopen.com

\section{InTech China}

Unit 405, Office Block, Hotel Equatorial Shanghai

No.65, Yan An Road (West), Shanghai, 200040, China

中国上海市延安西路65号上海国际贵都大饭店办公楼405单元

Phone: +86-21-62489820

Fax: +86-21-62489821 
(C) 2010 The Author(s). Licensee IntechOpen. This chapter is distributed under the terms of the Creative Commons Attribution-NonCommercialShareAlike-3.0 License, which permits use, distribution and reproduction for non-commercial purposes, provided the original is properly cited and derivative works building on this content are distributed under the same license. 